\title{
The relationship between economic preferences and psychological personality measures
}

Citation for published version (APA):

Becker, A., Deckers, T., Dohmen, T. J., Falk, A., \& Kosse, F. (2012). The relationship between economic preferences and psychological personality measures. METEOR, Maastricht University School of Business and Economics. METEOR Research Memorandum No. 047 https://doi.org/10.26481/umamet.2012047

Document status and date:

Published: 01/01/2012

DOI:

10.26481/umamet.2012047

Document Version:

Publisher's PDF, also known as Version of record

\section{Please check the document version of this publication:}

- A submitted manuscript is the version of the article upon submission and before peer-review. There can be important differences between the submitted version and the official published version of record.

People interested in the research are advised to contact the author for the final version of the publication, or visit the DOI to the publisher's website.

- The final author version and the galley proof are versions of the publication after peer review.

- The final published version features the final layout of the paper including the volume, issue and page numbers.

Link to publication

\footnotetext{
General rights rights.

- You may freely distribute the URL identifying the publication in the public portal. please follow below link for the End User Agreement:

www.umlib.nl/taverne-license

Take down policy

If you believe that this document breaches copyright please contact us at:

repository@maastrichtuniversity.nl

providing details and we will investigate your claim.
}

Copyright and moral rights for the publications made accessible in the public portal are retained by the authors and/or other copyright owners and it is a condition of accessing publications that users recognise and abide by the legal requirements associated with these

- Users may download and print one copy of any publication from the public portal for the purpose of private study or research.

- You may not further distribute the material or use it for any profit-making activity or commercial gain

If the publication is distributed under the terms of Article $25 \mathrm{fa}$ of the Dutch Copyright Act, indicated by the "Taverne" license above, 
Anke Becker, Thomas Deckers, Thomas Dohmen, Armin Falk, Fabian Kosse

The Relationship Between Economic Preferences and Psychological Personality Measures

$\mathrm{RM} / 12 / 047$

\section{METEOR}

Maastricht University School of Business and Economics Maastricht Research School of Economics

of Technology and Organization

\section{P.O. Box 616}

NL - 6200 MD Maastricht

The Netherlands 


\title{
The Relationship Between Economic Preferences and Psychological Personality Measures*
}

\author{
Anke Becker \\ Thomas Deckers \\ Thomas Dohmen \\ University of Bonn \\ University of Bonn \\ Maastricht University \\ Armin Falk ${ }^{\dagger}$ \\ Fabian Kosse \\ University of Bonn \\ University of Bonn
}

\begin{abstract}
Although both economists and psychologists seek to identify determinants of heterogeneity in behavior, they use different concepts to capture them. In this review we first analyze the extent to which economic preferences and psychological concepts of personality - such as the Big Five and locus of control - are related. We analyze data from incentivized laboratory experiments and representative samples and find only low degrees of association between economic preferences and personality. We then regress life outcomes - such as labor market success, health status and life satisfaction - simultaneously on preference and personality measures. The analysis reveals that the two concepts are rather complementary when it comes to explaining heterogeneity in important life outcomes and behavior.
\end{abstract}

Keywords: risk preference, time preference, social preferences, Locus of Control, Big Five

JEL-Codes: C91, D01, D80, D90, I00, J30, J62

\footnotetext{
*We gratefully acknowledge support by the European Research Council (Starting Grant).

${ }^{\dagger}$ Corresponding author: Armin Falk, Department of Economics, University of Bonn, Adenauerallee 24-42, 53113 Bonn, Germany (e-mail: armin.falk@uni-bonn.de)
} 


\section{Introduction}

Both economists and personality psychologists seek to identify determinants of heterogeneity in behavior. Economists typically depict decision problems in a framework of utility maximization. An individual's utility is shaped by preferences such as risk, time, and social preferences. ${ }^{1}$ These preferences, in combination with expectations of future events, perceptions, beliefs, strategic consideration, prices and constraints shape behavior. Personality psychology, the branch of psychology studying personality and individual differences, offers several frameworks describing universal traits and individual differences. Personality traits - defined by Roberts (2009, p. 140) as "the relatively enduring patterns of thoughts, feelings, and behaviors that reflect the tendency to respond in certain ways under certain circumstances" - are important determinants of personality (Roberts, 2006) and affect outcomes. There has been a long tradition in personality psychology to measure personality traits. The Big Five or five-factor model is the most widely used taxonomy of personality traits. It originates from the lexical hypothesis of Allport and Odbert (1936), which postulates that individual differences are encoded in language (see Borghans et al. 2008). After years of research in this tradition, psychologists have arrived at a hierarchical organization of personality traits with five traits at the highest level. These Big Five traits, which are commonly labeled as openness to experience, conscientiousness, extraversion, agreeableness, and neuroticism, capture personality traits at the broadest level of abstraction. Each Big Five trait condenses several distinct and more narrowly defined traits. It has been argued that the bulk of items that personality psychologists have used to measure personality

\footnotetext{
${ }^{1}$ In the standard expected utility framework, risk preference is captured by the curvature of the utility function, whereas the degree of risk aversion is represented in the concavity of the utility function (e.g. Gollier, 2001). Time preference describes how an individual trades off utility at different points in time (Samuelson, 1937; Frederick et al., 2002). Social preferences capture the idea that an individual's utility does not depend only on his own material payoff, but that it is also shaped by others' behavior and material payoff. Social preferences include altruism (e.g. Eckel and Grossmann, 1996) and negative and positive reciprocity (e.g. Falk and Fischbacher, 2006). Finally, trust describes an individual's belief about others' trustworthiness combined with a preference to take social risks (e.g. Fehr, 2009). Another important economic preference is the preference for work versus leisure. This preference is difficult to measure in experiments and is therefore not part of our analysis.
} 
can be mapped into the Big Five taxonomy (see, e.g., Costa and McCrae, 1992)). ${ }^{2}$ Another important concept in psychology focusing on individual beliefs and perceptions is the locus of control framework by Rotter (1966). It represents the framework of the social learning theory of personality and refers to the extent people believe they have control over events.

An integration of the different measures and concepts used by economists and personality psychologists promises much potential for amalgamating evidence about the drivers of human behavior which accumulated disjointedly in the fields of economics and psychology (Borghans et al., 2008). Recently, scholars have begun to integrate personality into economic decision making (e.g., Borghans et al., 2008). Almlund et al. (2011) enrich theory by incorporating personality traits in a standard economic framework of production, choice, and information. Their model interprets measured personality as a "construct derived from an economic model of preferences, constraints, and information" (Almlund et al., 2011, p. 3). However, empirical knowledge is too limited to judge how personality traits relate to the concepts and parameters economists typically model to predict behavior.

To shed more light on the relationship between economic preferences and psychological measures of personality we therefore study how key economic preferences, such as risk, time and social preferences, are linked to conventional measures of personality, such as the Big Five and locus of control. We analyze this relationship in a coherent framework using two main approaches. The first approach focuses on assessing the magnitude of the correlations between psychological and economic measurement systems in three unique data sets. The second approach departs from the fact that both preference measures and measures of personality traits predict a wide range of important life outcomes. If these two measurement systems are closely linked, they are expected to be substitutes in explaining heterogeneity in behavior. If, however, preferences and personality traits capture different aspects of behavior, the two measurement systems may have complementary predictive power for important life outcomes. We therefore evaluate the individual as well as the joint explanatory power of economic preferences and psychological measures of personality in explaining health, educational and labor market outcomes.

\footnotetext{
${ }^{2}$ For a more detailed description of the research on the development of the Big Five, criticism of the approach and alternative measurement systems see Borghans et al. (2008).
} 
We use three complementary datasets. First, we look at data from laboratory experiments. Using a student subject pool we conducted choice experiments on key economic preferences, namely risk taking, time discounting, altruism, trust, and positive and negative reciprocity. We incentivized decision-making and obtained multiple behavioral measures for each preference. We assessed the Big Five domains using the 60-item NEO-FFI (NEO Five Factor Inventory) (Costa and McCrae, 1989) and a 15-item subset, the so-called BFI-S (Gerlitz and Schupp, 2005). We also measured the locus of control using 10 items adapted from Rotter (1966). Our second data set comprises very similar incentivized experimental measures with respect to risk taking and time discounting using a representative sample of almost 1000 participants from the German population. We are therefore able to obtain incentivized preference measures for a representative population. Personality was assessed using the BFI-S. The third data set stems from the German Socio-Economic Panel Study (SOEP), comprising preference and personality measures for a representative sample of more than 14.000 individuals. Preference measures were obtained using subjective self-assessment survey items rather than incentivized experiments, and personality was measured by using the BFI-S and the locus of control questionnaire. Using this data set we analyze associations between important life outcomes, such as labor market success, subjective health status or life satisfaction, and individuals' preferences and personalities.

These three data sets allow for a comprehensive analysis. The first data set contains very detailed personality measures in combination with multiple experimental indicators for preferences. This student sample therefore provides a particularly accurate assessment of potential relations between economic preferences and personality. The second data set uses experimental measures for a limited set of preferences and a shorter version of the Big Five but a representative sample. A comparison of results of the two data sets therefore informs us about the generalizability of our findings from the student sample. The third data set additionally allows us to study an even larger sample and to explore the explanatory power of personality and preferences for important life outcomes.

We start by analyzing data on 489 university students. We relate all five factors that capture personality according to the Big Five taxonomy and the measure of Locus of Control to our experimental preference measures. We generally find only small correlations 
between personality traits and preferences. In particular, only 11 of the 36 correlations in our student sample exceed 0.1 in absolute value and only one correlation exceeds 0.2 in absolute value. These eleven correlation coefficients are all significant at conventional levels, and eight of them involve correlations between social preferences and personality traits.

Next, we gauge whether the correlation patterns generalize to representative samples. We first turn to the data set that contains very similar experimental measures of risk and time preferences and survey measures of the Big Five approximately 1000 individuals, who were sampled to be representative of the adult population living in Germany (see Dohmen et al., 2010). The correlation structure between personality traits and risk and time preferences turns out to be similar to the one we find for students, with few exceptions.

Finally, we assess whether the empirical associations between preference parameters and personality traits are sensitive to the way in which preferences are measured. We compare correlations between personality traits and measures of preferences derived from the incentivized choice experiments in the student and the representative sample to correlations that are constructed based on the non-incentivized subjective self-assessments in a representative sample of 14.000 individuals from the SOEP. Our result on the pattern of correlations between preference measures and personality measures is again largely confirmed.

We then turn to a different type of analysis in which we assess the power of preferences and personality in explaining life outcomes, including health, life satisfaction, earnings, unemployment and education. Our analysis reveals that both measurement systems have similar explanatory power when used separately as explanatory variables. The explained fraction of variance increases by approximately $60 \%$ when life outcomes are regressed on both measurement systems. We therefore conclude that each measurement system captures distinct sources of the heterogeneity in life outcomes. A coherent picture emerges from our analysis. Both approaches strongly suggest that standard measures of preferences and personality are complementary constructs.

So far no clear picture concerning the relations between measures of personality and economic preferences has emerged in the literature (see Almlund et al., 2011). For example, 
the study by Daly et al. (2009) suggests a negative relationship between conscientiousness and the discount rate, but such a negative correlation is not corroborated by Dohmen et al. (2010), who relate experimental measures of willingness to take risk and impatience to survey measures of the Big Five in a representative sample of adults living in Germany, nor by Anderson et al. (2011), who relate a measure of delay acceptance to four of the Big Five domains in a sample of 1065 US trainee truckers. ${ }^{3}$ In fact, Dohmen et al. (2010) find no significant relationship between personality traits and preference measures in a regression framework that includes controls for IQ, gender, age, height, education, and household income. Raw correlations between preference and personality measures, which are also reported in Almlund et al. (2011), are weak; time preference is significantly correlated only to agreeableness (at the 10 percent level). ${ }^{4}$ This finding is confirmed by the significant correlation between delay acceptance and agreeableness in the truck-driver sample of Anderson et al. (2011).

Evidence on the link between risk preferences and the Big Five domains is equally mixed. Raw correlations between a lottery-choice measure of risk preference and personality traits in the data from Dohmen et al. (2010) indicate significant relationships between risk preferences and openness to experience (at the 1 percent level) and agreeableness (at the 5 percent level). Anderson et al. (2011) do not measure openness to experience. They do not find a significant correlation for risk preference and agreeableness, but report a weak correlation between risk preference and neuroticism (0.05 in absolute value), which is significant at the 10 percent level. This finding is in line with the significant positive association between risk aversion and neuroticism reported by Borghans et al. (2009). Other researchers (e.g. Zuckerman, 1994) have related risk preferences to sensation seeking, a facet of extraversion in the Big Five taxonomy, and found mixed evidence. Whereas Bibby and Ferguson (2010) report a significant correlation between a measure of loss aversion and sensation seeking $(r=0.27)$, Eckel and Grossmann (2002) find no evidence of an association between risk preferences and sensation seeking.

Evidence on the link between social preferences and personality is somewhat stronger.

\footnotetext{
${ }^{3}$ The effect sizes of the correlations between preference and personality measures are all smaller than 0.1 in absolute value.

${ }^{4}$ We report this data in Table 3.
} 
Dohmen et al. (2008) relate survey measures of social preferences to measures of the Big Five using data from the SOEP and find significant associations between trust, as well as positive and negative reciprocity and personality traits. Trust is related positively to agreeableness and openness to experience, and negatively to conscientiousness and neuroticism; while positive reciprocity is positively associated with all five personality factors, negative reciprocity is related negatively to conscientiousness and extraversion, and positively to neuroticism. A link between extraversion and behavior in the dictator game, which can be interpreted as a measure of altruism, has been established by Ben-Ner and Kramer (2010).

This review is structured as follows. Section 2 describes our three data sets. In Section 3 we introduce our research strategy for investigating the link between personality and preferences. Section 4 presents evidence on the correlation between measures of personality and measures of preferences. In addition it contains an assessment of the explanatory power of preferences and personality in explaining important life outcomes. Section 5 concludes.

\section{Data and Measures}

In this section, we provide a description of the three complementary data sets that we employ for our analysis. Before we present our experimental and survey measures in detail, a few comments on identification are warranted. Economists typically try to infer preferences from choices, the so-called revealed preference approach. For example, one might surmise that a person who does not wear a safety belt an who invests in risky stocks has a preference for taking risks. It is, however, easy to show that the same behavioral pattern is compatible with very different risk preferences if other factors affect the person's decisions. For example, differences in beliefs about how risky driving without a safety-belt or investing in stocks actually is may affect decisions equally strong than underlying risk preferences. The problem is that the decision context is uncontrolled and person specific, rendering precise statements about preference parameters very difficult. ${ }^{5}$ This is why economists

\footnotetext{
${ }^{5}$ Conceptually identical problems apply to the identification of traits, such as ability, physical strength and personality characteristics from observed performance on tasks, when performance also depends on other unobserved factors such as time, energy and attention devoted to the task. An illuminating discussion
} 
run experiments to infer preferences. In a typical choice experiment subjects make decisions in a well-controlled decision environment. In risk experiments, for example, stakes and probabilities are fixed and the action space is identical for every subject. Observing subjects' decisions in a controlled experimental environment therefore rules out many potentially confounding factors, allowing a more precise identification of preferences. Even in an experiment, however, the identification of preferences is limited (see Manski (2002) for a thorough discussion on the identification of experimental outcomes). The same observed action can reflect different risk attitudes, for example, if the experimental subjects dispose of different wealth levels and the curvature of the utility function is not invariant to wealth levels. Despite these limitations experiments deliver much more precise behavioral outcomes than non-experimental observations. In strategic situations, which are relevant for measuring trust and reciprocity, we are able to elicit not just an action but a complete strategy. With field observations this is impossible. The relevance of eliciting a strategy is obvious: Suppose one observes a second mover who defects in a cooperation context, in response to a non-cooperative act of a first mover. This could reveal selfish preferences as well as reciprocal preferences. Disentangling the two requires knowledge about what the decision maker would have done, had the first mover cooperated. Eliciting a strategy instead of observing only actions does exactly this. Experimental observations have the additional advantage over survey responses that decisions have immediate monetary consequences. This is of obvious importance, for example, for identifying altruism. There is a big difference between simply stating altruistic preferences and revealing them in a costly manner.

\section{$2.1 \quad$ Experimental Data}

The first data set consists of decisions from laboratory experiments among university students. We ran a series of simple incentivized choice experiments to elicit preferences concerning risk taking, discounting, positive and negative reciprocity, and trust as well as altruism. ${ }^{6}$ Table 1 presents an overview of the experiments and provides a short description of the identification problem is provided in section 3 of Almlund et al. (2011).

${ }^{6}$ For a detailed description of the experimental procedures see Falk et al. (2011). 
of the elicitation methods and the obtained behavioral measures. Four important features about our experimental design are worth noting. First, subjects took part in two very similar experiments each for risk taking, discounting, trust and positive reciprocity. This allows us to average over both outcomes for each subject in order to minimize measurement error. Second, to reduce spillovers between different choices, we ran the experiments not in one single session but in two sessions, which were scheduled one week apart. ${ }^{7}$ Third, to reduce possible income effects with respect to outcomes within a session, we gave feedback about experimental outcomes only at the end of an experimental session. Fourth, the vast majority of subjects in the experiments had never taken part in an experiment before. This eliminates possible confounds in behavior due to previous experiences in similar experiments. In total, 489 students from different majors from the University of Bonn participated. ${ }^{8}$ The experiments were run at the Laboratory for Experimental Economics at the University of Bonn (BonnEconLab). We used zTree (Fischbacher, 2007) as experimental software and recruited subjects using ORSEE (Greiner, 2004). Each session lasted about two hours, and average earnings were 64 Euros.

\footnotetext{
${ }^{7}$ We reversed the order of the sessions for half of the subjects. Statistical tests reveal no significant order effects.

${ }^{8}$ Out of these 489 students, 80 took part in a pretest of the study. Most of these 80 subjects had taken part in an experiment before. The pretest did not include the experiments on altruism and negative reciprocity.
} 
Table 1: Overview of the experimental measures in data set from laboratory experiments amon university students

\begin{tabular}{l|l|l}
\hline \hline Preference & \multicolumn{1}{c}{ Experiment } & \multicolumn{1}{c}{ Measure } \\
\hline Time & $\begin{array}{l}\text { Two lists of choices between } \\
\text { an amount of money "today" } \\
\text { and an amount of money } \\
\text { "in } 12 \text { months". }\end{array}$ & $\begin{array}{l}\text { Average switching point } \\
\text { over both lists of choices } \\
\text { from the early to the } \\
\text { delayed amount. }\end{array}$ \\
\hline Risk & $\begin{array}{l}\text { Two lists of choices between } \\
\text { a lottery and varying safe } \\
\text { options. }\end{array}$ & $\begin{array}{l}\text { Average switching point } \\
\text { over both lists of choices } \\
\text { from the lottery to the } \\
\text { safe option. }\end{array}$ \\
\hline Positive & $\begin{array}{l}\text { Second-mover behavior in two } \\
\text { versions of the trust game } \\
\text { (strategy method). }\end{array}$ & $\begin{array}{l}\text { Average amount sent back } \\
\text { in both trust games. }\end{array}$ \\
\hline Negative & $\begin{array}{l}\text { Investment into punishment after } \\
\text { unilateral defection of the opponent } \\
\text { in a prisoner's dilemma } \\
\text { (strategy method). }\end{array}$ & $\begin{array}{l}\text { Amount invested into } \\
\text { punishment. }\end{array}$ \\
\hline Trust & $\begin{array}{l}\text { First mover behavior in two } \\
\text { versions of the trust game. }\end{array}$ & $\begin{array}{l}\text { Average amount sent as } \\
\text { a first mover in both } \\
\text { trust games. }\end{array}$ \\
\hline Altruism & $\begin{array}{l}\text { First mover behavior in a } \\
\text { dictator game with a charitable } \\
\text { organization as recipient. }\end{array}$ & Size of donation. \\
&
\end{tabular}

\subsubsection{Preference Measures}

Risk Preferences To elicit risk attitudes we adapted the design from Dohmen et al. (2010). Subjects were shown a list of binary alternatives, a lottery and a (varying) safe option. The lottery was the same for each decision: If they chose the lottery participants could receive either 1000 points or zero points with 50 percent probability each. The safe option increased from row to row, starting from a value of (close to) zero, and increasing up to a value of (close to) the maximum payoff of the lottery. To reduce measurement error subjects participated in two risk experiments. The choice list of the second experiment was simply a perturbed version of the first one. Perturbations were constructed such that 
a randomly drawn integer value between -5 and +5 was added to the safe option in every choice, corresponding to perturbations of maximally $5 \%$ of the step size of the increase in the safe option. The complete list of choices was shown to subjects on the first screen. Each choice situation was then presented on a separate screen, where subjects entered their respective choice. Subjects were informed that one choice in each list would be selected randomly and paid. Subjects with monotonic preferences should choose the lottery for lower safe options and switch to the safe option when the latter reaches or exceeds the level of their certainty equivalent. Thus switching points inform us about individual risk attitudes. The earlier a subject switches to the save option the less she is willing to take risks. For our analysis we constructed a risk preference measure using the average of the two switching points from the two experiments. ${ }^{9}$

Time Preferences To measure individuals' time preferences we implemented a procedure very similar to the one for risk attitudes. In the discounting experiments, subjects were given two lists of choices between an earlier amount of money ("today"), which was the same in all choices, and an increasing delayed amount of money ("in 12 months"). In the first row, the early amount was equal to the delayed amount. Delayed amounts increased from row to row by $2.5 \%$. As for risk preferences subjects participated in a very similar second discounting experiment with small perturbations of delayed amounts between +0.5 and -0.5 percentage points. One choice in each of the two lists was randomly selected for payment. Payments resulting from the two experiments were sent to subjects via regular mail. If a subject chose the early amount, the payment was sent out on the day of the experimental session. If a subject chose the delayed amount, the payment was sent out with a delay of 12 months. ${ }^{10}$ The switching point from early to delayed payment informs us about a subject's time preference. Subjects who switch later discount the future amount by more (i.e., are less patient) than subjects who switch earlier. ${ }^{11}$ Our measure

\footnotetext{
${ }^{9}$ If subjects switched between the lottery and the safe option more than once, we took the average switching row as an estimate of their certainty equivalent. This happened in $16 \%$ of the cases in the first experiment on risk taking, and in $11 \%$ of the cases in the second experiment.

${ }^{10}$ Keeping the payoff mode identical over both time horizons rules out credibility concerns.

${ }^{11}$ For subjects, who switched more than once, we took the average switching row as an estimate of their discount rate. This happened in $5 \%$ of the cases in the first experiment on time discounting, and in $7 \%$
} 
of individual discounting is the average switching row in both lists. To ease interpretation of the correlations reported below, we recode the measure, such that higher values imply earlier switching rows, i.e., a higher level of patience.

Trust We elicited trust from first-mover behavior in the so-called trust game (Berg et al., 1995). We conducted two versions of the trust game. In one version, the amount sent by the first mover was doubled by the experimenter, whereas in the second version the amount was tripled. Every subject was in the role of the first and of the second mover twice. $^{12}$ Both trust games were incentivized, i.e., every (relevant) decision was paid. In the role of a first mover, subjects could choose to send any amount in $\{0,50,100, \ldots, 500\}$ points to the second mover. All interactions in the trust game as well as in all other social preference experiments were one-shot and anonymous (perfect stranger matching protocol). The average amount sent as a first mover in both trust games constitutes our experimental measure for trust: Subjects who send higher amounts of money are those who display higher levels of trust.

Positive Reciprocity To elicit positive reciprocal inclinations we measure subjects' second-mover behavior in the trust game (see above). We implemented the strategy method (Selten, 1967). This means that for every possible amount sent by the first mover, subjects were asked to indicate how much they wanted to send back. The actual decision of the first mover determined which of these decisions became payoff relevant. The average amount sent back as a second mover in both trust games was taken as individuals' willingness to reciprocate, such that higher values imply a higher willingness to reciprocate.

Negative Reciprocity To measure subjects' willingness to engage in costly punishment of unfair behavior, we conducted a prisoner's dilemma with a subsequent punishment stage. ${ }^{13}$ In the punishment stage, subjects could choose to invest points in order to deduct points from their opponent. Punishment was costly. Again, we implemented the strategy

of the cases in the second experiment.

${ }^{12}$ Overall, we therefore ran four trust games.

${ }^{13}$ The design of the experiment was adapted from Falk et al. (2005) 
method. Before taking their decisions in the first stage of the experiment (i.e., in the prisoner's dilemma) subjects were asked to indicate how many points they wanted to deduct from the other player in case he cooperated or defected, for both own cooperation and own defection. Then they played a simultaneous prisoner's dilemma. The outcome of the first stage determined which choice of the second stage became payoff relevant. The chosen investment into punishment after unilateral defection of the other player served as a measure of an individual's willingness to reciprocate negatively.

Altruism To measure altruistic behavior we had subjects take part in a modified dictator game in which the recipient was a charitable organization (adapted from Eckel and Grossmann, 1996). Subjects were endowed with 300 points and had to decide how much of this endowment to donate to a charitable organization. ${ }^{14}$ This decision serves as our experimental measure of subjects' altruistic inclination.

\subsubsection{Personality Measures}

Big Five As part of the study, subjects were given a paper-and-pencil survey, which they were asked to fill out at home and return to us via mail. ${ }^{15}$ Of the 489 subjects, 319 completed the survey and sent it back to us. The survey included the NEO-FFI version of the Big Five (Costa and McCrae, 1989). During the experimental sessions, all 489 subjects also answered a shorter version of the NEO-FFI: the BFI-S, a subset consisting of 15 items. The BFI-S has been developed by Gerlitz and Schupp (2005) and was also part of the 2005 and 2009 waves of the SOEP. Correlations between the long version and the short version of the Big Five differ between the five personality dimensions. The lowest correlation is $r=0.48$ for openness, and the highest is $r=0.71$ for conscientiousness (all $p$-values $<0.001)$. We constructed our Big Five measure in that we use data from the long version whenever available, while for the remaining subjects we refer to the short version. That way, we have measures of the Big Five domains for all 489 subjects.

\footnotetext{
${ }^{14}$ Subjects could choose a charitable organization from a list, or name one themselves.

${ }^{15} \mathrm{We}$ also handed out stamped envelopes with the address of our research institute, in order to minimize additional costs for returning the survey to us.
} 
Locus of Control The paper-and-pencil survey included 10 items that allows us to construct a measure of the locus of control for the 319 individuals who filled in the survey. These 10 items have been adapted from Rotter (1966) and they have also been implemented in the 2005 wave of the SOEP. The personality construct of locus of control assesses how much people believe they have control over their life outcomes, or how much their lives are determined by forces that are outside of their control, such as luck or faith. We constructed the measure such that higher values represent a more internal locus of control, i.e., the belief that the person can influence their life outcomes. Lower values represent a more external locus of control.

\subsection{Representative Experimental Data}

The second data set we employ consists of experimental data for a representative sample of the German population. ${ }^{16}$ This data set is used to assess whether the findings from the sample of university students can be corroborated in a representative sample. Subjects' risk and time preferences were elicited, and we again have information on participants' personality. The data used here stem from a study conducted in 2005 and contains information on 1012 individuals. For a detailed description of the study and its procedures see Dohmen et al. (2010).

Preference Measures The experiments on risk and time preferences were similar to the ones we used in the laboratory experiments. In both experiments subjects had to make multiple decisions in a list of choices. To elicit their risk preferences we had subjects choose between a lottery, which remained the same in all choices, and safe options, which increased in their value. As in the experiments discussed above, the switching point informs us about the individual's willingness to take risks. Similarly, to elicit individuals' time preferences we had all participants make a number of intertemporal choices. They had to decide between an amount "today" and a larger amount "12 months" later. The early amount remained

\footnotetext{
${ }^{16}$ The same data set is used in Dohmen et al. (2010).
} 
the same in all choices. The first delayed amount presented to subjects was devised to imply a $2.5 \%$ return on the early amount assuming semi-annual compounding. In the subsequent choices the delayed payment was gradually increased and was calculated such that the implied rate of return rose in steps of 2.5 percentage points. Again, the switching points from the early to the delayed option inform us about the subjects' time preferences.

Personality Measures The five personality domains were assessed using the BFI-S (see Section 2.1.2 for a more detailed description).

\subsection{Representative Panel Data}

The third data set we use stems from the SOEP, a large panel data set that is representative of the adult population living in Germany (see Schupp and Wagner (2002) and Wagner et al. (2007) for a detailed description of the SOEP). We use information from eight waves collected in the years between 2003 and 2009. In each of these waves more than 20,000 individuals were interviewed. The SOEP combines extensive sociodemographic information with various measures of attitudes, preferences and psychological traits. In particular, the SOEP includes survey items relating to all personality and preference measures that we discuss in the previous sections.

Personality and economic preference measures were elicited several times between 2003 and 2009. To construct a measure for each individual, we use the maximum available number of observations of a given measure. If several measures of personality and preferences are available, we take the average of the standardized measures of all years in which this measure was elicited. The resulting average is then standardized as well. In case a particular measure was elicited only in one wave (e.g., as it is the case for patience) we just take the standardized measure from that respective year. We restrict the sample to individuals for whom we have information about each personality and preference measure. This results in a sample size of 14,243 individuals.

Preference Measures As a measure for time preference we use answers to the following survey question: "How would you describe yourself: Are you generally an impatient person, 
or someone who always shows great patience?". ${ }^{17}$ Participants gave an answer on an 11point scale where zero means "very impatient" and 10 means "very patient". This survey question was implemented in the SOEP only in 2008. The risk preference question is worded in the same manner: "How do you see yourself: Are you generally a person who is fully prepared to take risks, or do you try to avoid taking risks?" Answers were given on an 11-point scale, where zero means "unwilling to take risks" and 10 means "fully prepared to take risks". This question was included in the 2004, 2006, 2008 and 2009 waves. The general risk question has been studied in various papers and has been validated using incentivized experiments in representative samples as well as through behavioral evidence in Dohmen et al. (2011). In 2005 the SOEP contained six items to measure reciprocal inclinations, three items each on positive and negative reciprocity. Examples for positive and negative reciprocity are as follows: "If someone does me a favor, I am prepared to return it" and "If I suffer a serious wrong, I will take revenge as soon as possible, no matter what the costs". Participants expressed how well these six statements apply to them on a seven-point Likert scale. For a detailed description see Dohmen et al. (2009). Standard trust questions were included in the 2003 and 2008 waves, using three sub-statements about whether "one can trust people", whether "in these times one can't rely on anybody else" and whether "when dealing with strangers it is better to be cautious". Answers were given on a five-point scale ranging from "totally agree" to "totally disagree". Finally, our survey measure for altruism is the answer to the question of how important it is for the participant "to be there for others". Answers were given on a four-point scale. The altruism question was asked in the 2004 and 2008 waves.

Personality Measures The 2005 and 2009 waves of the SOEP contained the BFI-S questionnaire, developed by Gerlitz and Schupp (2005). The locus of control was elicited in 2005 using Rotter's (1966) locus of control scale. Both inventories were also used in our laboratory experimental data (see Section 2.1.2 for more details on the BFI-S and the locus of control scale).

\footnotetext{
${ }^{17}$ The behavioral validity of this question with respect to incentivized experiments is documented in Vischer et al. (2011).
} 


\section{Research Strategy}

To answer the question of whether measures of personality and economic preferences are closely linked we first study the raw correlations between these measures. High correlations would indicate some degree of substitutability. Low correlations, conversely, would suggest that the two measurement systems are complementary concepts in explaining heterogeneity in behavior. Whether a correlation should be interpreted as "high" or "low" is of course always debatable. We therefore first look at statistical significance levels. Statistical significance, however, can also be found for correlations that are low in terms of effect size (Cohen, 1992). Following conventions in the social sciences we interpret effect sizes, i.e., correlations $r$, as rather "low" if $r$ is between 0.1 and 0.3 , as "medium" if $r$ is between 0.3 and 0.5 and as "large" if $r$ is larger than 0.5. Because the analysis of correlations is restricted to linear relations, we also check for potential non-linear associations by conducting non-parametric regressions. In particular, we look at kernel-weighted local linear polynomial regressions.

We then check to see whether measures of personality and preferences are substitutes or complements in terms of their explanatory power for life outcomes. In particular, we conduct linear regressions and assess the explanatory power of the two concepts by reporting levels of adjusted $R^{2}$. In these regressions, measures of personality and preferences are included individually as well as jointly. If the two measurement systems are substitutes, adjusted $R^{2}$ in the combined regressions should not be distinctly higher than in regressions that include only one of the two concepts. The opposite should hold for complements. Additionally, we investigate model selection criteria in these regressions. We check for robustness using binary and ordered choice models as well as more comprehensive specifications including square terms and cross-products of all regressors.

\section{Results}

In this section we discuss our main findings. To ease comparison between data sets and measures, we standardized all experimental as well as all personality measures for the data 
analysis.

\subsection{Correlation Structure}

\subsubsection{Experimental Data}

Table 2 displays the 36 raw correlations of the personality and economic preference measures obtained from the laboratory experiments. A first inspection of Table 2 reveals that only 11 of these 36 correlations are statistically significant at the $5 \%$ or $1 \%$ level. ${ }^{18}$ All correlation coefficients are smaller than 0.3 in absolute value. Hence there is no correlation with a "medium" effect size or larger. Moreover, of the 36 correlations only 11 exceed 0.1 in absolute value and only 1 slightly exceeds $0.2{ }^{19}$

Table 2 also shows that among all personality factors agreeableness exhibits the highest and statistically most significant correlations with measures of economic preferences. It is significantly correlated with measures for positive and negative reciprocity, trust and altruism (all $p$-values $<0.01)$ as well as with time preference $(p$-value $<0.05)$. Correlations with social preferences range between 0.1 and 0.3 in absolute value, indicating a small effect size according to the classification of Cohen (1988). The high frequency of significant correlations of agreeableness with social preferences is not surprising as the former is defined as "the tendency to act in a cooperative, unselfish manner,..." (see Table A.1).

The finding of only moderate correlations between preference and personality measures does not necessarily indicate that these constructs are weakly connected; it indicates only that there are weak linear relations. For example, a perfect U-shaped relation between a personality factor and a preference would result in an insignificant linear correlation. To explore the possibility of non-linear relationships we therefore estimate kernel-weighted local linear polynomial regressions. ${ }^{20}$ In each regression, we restrict the sample to a range of

\footnotetext{
${ }^{18}$ Five additional correlations are weakly significant, i.e., significant at the $10 \%$ significance level.

${ }^{19}$ Results qualitatively stay the same when investigating Spearman correlations instead of Pearson correlations (see Table A.2 in the appendix). Moreover, when looking at a potential linear mapping, i.e., linear regressions of either the Big Five on preferences or vice versa, $R^{2}$ is always below $10 \%$.

${ }^{20}$ We use the Epanechikov kernel and bandwidth is selected via the plugin estimator of the asymptotically optimal constant bandwidth.
} 


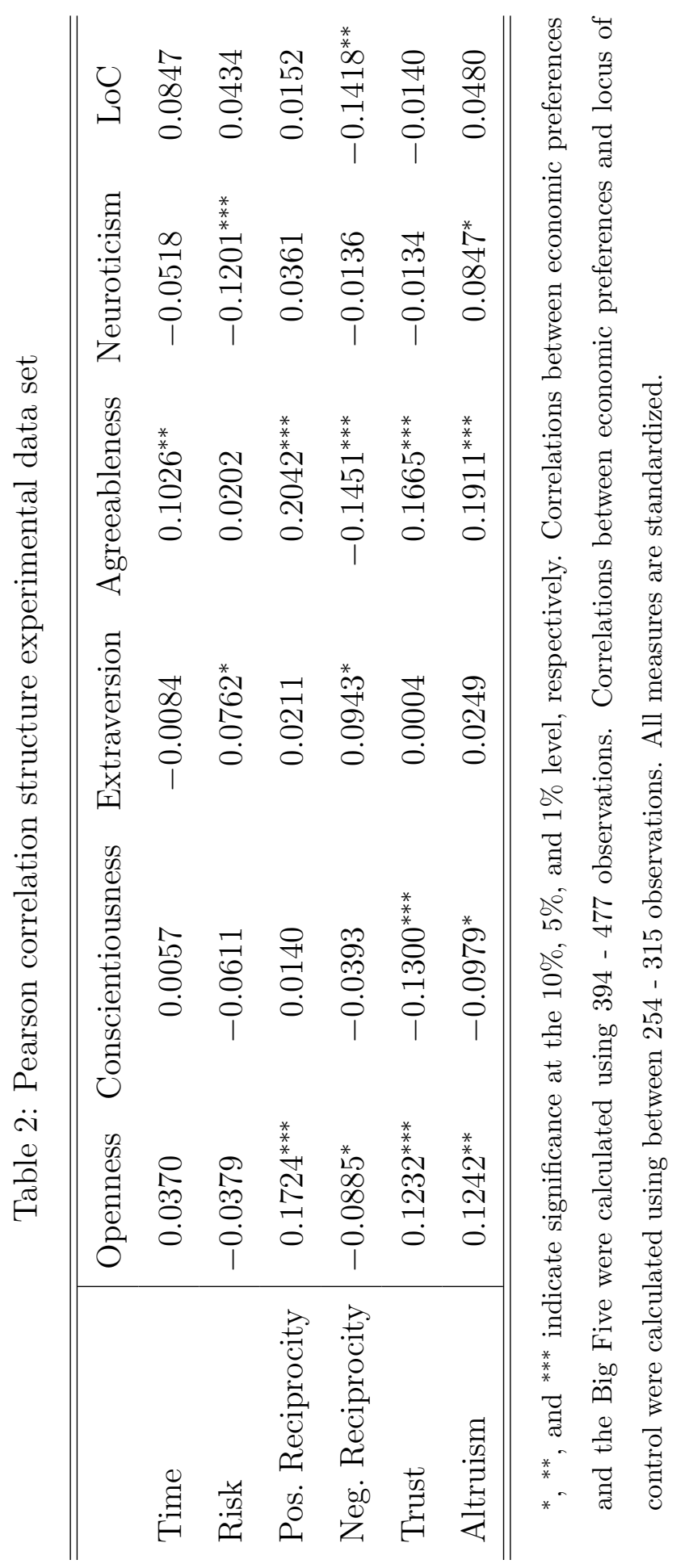


four standard deviations around the mean of each variable to circumvent an analysis biased by outliers. Therefore, the results are calculated using $70 \%$ to $97 \%$ of all observations. The predicted regressions are displayed in Figure A.1. Although sometimes there are small deviations from linearity at the boundaries, the overall picture strongly suggests a linear relation in the vast majority of combinations.

Summarizing our analysis of the laboratory experimental data, we find that associations between preference and personality measures are linear and that the degree of association is rather low, suggesting a complementary relationship. We next turn to the question of whether the correlation patterns observed in student samples can be replicated in a sample that is representative of the adult population. 


\subsubsection{Representative Experimental Data}

Table 3: Pearson correlation structure representative experimental data

\begin{tabular}{l|ccccc}
\hline \hline & Openness & Conscientiousness & Extraversion & Agreeableness & Neuroticism \\
Time & -0.0080 & -0.0682 & -0.0655 & $-0.0830^{*}$ & -0.0602 \\
Risk & $0.1356^{* * *}$ & -0.0720 & 0.0757 & $-0.0941^{* *}$ & -0.0290 \\
\hline \hline
\end{tabular}

${ }^{*},{ }^{* *}$, and ${ }^{* * *}$ indicate significance at the $10 \%, 5 \%$, and $1 \%$ level, respectively. All measures are standardized.

Table 3 shows the correlations between the outcomes from the risk and time experiments and the personality traits. As above, the measure for time is reversed so that higher values indicate higher patience. In terms of significance the pattern is similar to the one in the laboratory study. Only one correlation is significant at the $1 \%$-level, one is significant at the $5 \%$-level and one is significant at the 10\%-level. In terms of effect size, only the coefficient of the association between openness and risk preferences exceeds the 0.1 benchmark to be classified as a small correlation (Cohen, 1988). ${ }^{21}$ Interestingly, the sign is positive, in contrast to our laboratory data. The other two significant coefficients are even smaller. The analysis of representative data therefore confirms that the level of association between preference personality measures is rather small. However, we can draw this conclusion only with respect to time and risk preferences, as we do not have experimental data on trust and social preferences. We next analyze whether these findings also hold when looking at all preference measures in a large representative sample.

\subsubsection{Representative Panel Data}

In this section, we study whether our findings from the experiments generalize to a large representative sample using survey rather than experimental instruments for measuring economic preferences. Table 4 shows the raw correlations between personality measures and

\footnotetext{
${ }^{21}$ Results qualitatively stay the same when investigating Spearman correlations instead of Pearson correlations (see Table A.3 in the appendix).
} 


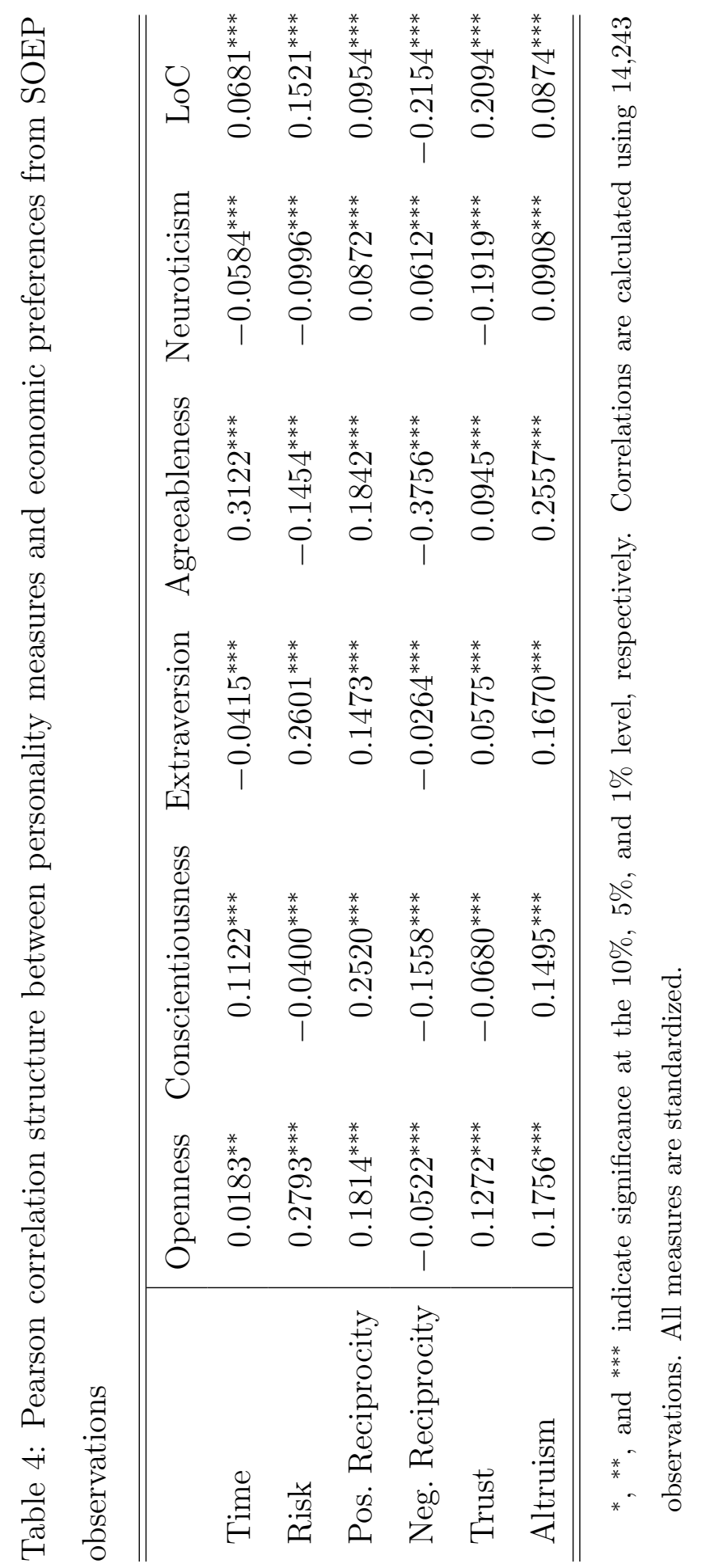


economic preferences using 14,243 observations from the SOEP. Given the large number of observations it is not surprising to find a large number of significant correlation coefficients ( $p$-values $<0.05$ for all correlation coefficients). In terms of effect size, however, only two correlations are of "medium" size, i.e., larger than 0.3. Of the reported 36 correlations, 18 can be classified as "small", whereas 16 correlations are even below 0.1 . This confirms the overall picture that emerged from the analysis of the two experimental data sets. ${ }^{22} \mathrm{~A}$ closer comparison of the SOEP survey measures with our experimental measures further reveals large similarities. As reported above, 11 correlations are significant at the $5 \%$ level in the experimental data. Ten of these correlations have the same sign and are significant at the $1 \%$ level using survey data. Moreover, as it is the case in the laboratory data set, the personality trait agreeableness exhibits the highest correlations with economic preferences, in particular social preferences. Although there are small differences in the results compared with the experimental data set (i.e., seven of the 36 correlation coefficients show a different sign), the general pattern emerging from the SOEP measures is consistent with our previous findings. Of the seven correlation coefficients only two are (weakly) significant in the experimental data set. Nevertheless, the inconsistency of signs brings into question the conjecture that correlations are universally identical (i.e., identical irrespective of age or other person characteristics). We return to this aspect in the final section.

We conclude this section with an analysis of potential non-linearities between our SOEP preference and personality measures. As for the laboratory experimental data, we perform kernel-weighted local linear polynomial regressions restricting the sample in each regression to four standard deviations above and below the mean. The resulting subsamples represent $92 \%$ to $97 \%$ of the observations of the main sample. The predicted functions presented in Figure A.2 show no particular non-linearities, except for some splines at the left ends of the considered range. Thus, analogous to the experimental data set, it is not

\footnotetext{
${ }^{22}$ Results qualitatively stay the same when investigating Spearman correlations instead of Pearson correlations (see Table A.4 in the appendix). Moreover, when looking at a potential linear mapping, i.e., linear regressions of either the Big Five on preferences or vice versa, $R^{2}$ is always around $15 \%$ with the exception of agreeableness, where $R^{2}$ reaches $28 \%$.
} 
the case that systematic non-linearities bias correlation coefficients.

\subsubsection{Explanatory Power for Life Outcomes}

Figure 1: Adjusted $R^{2}$ for Life Outcomes

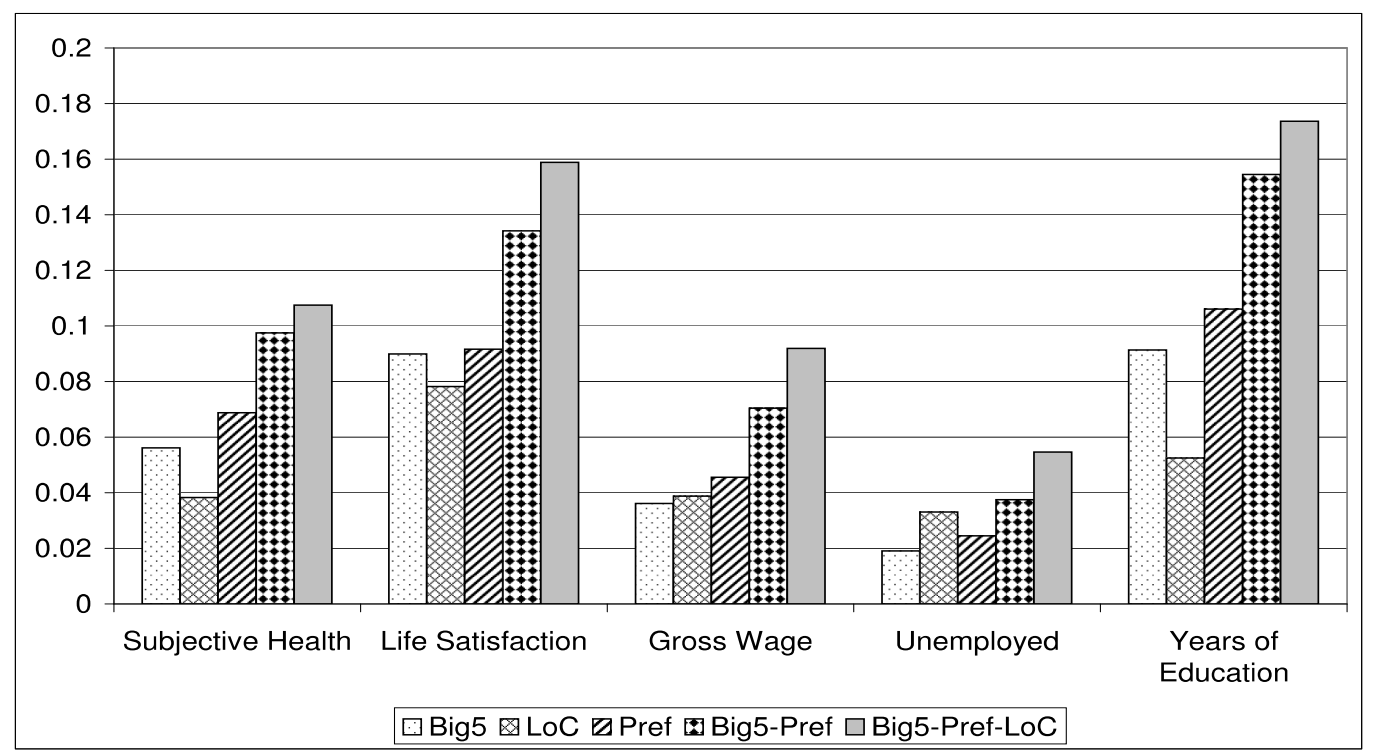

Adjusted $R^{2}$ 's for linear regressions for life outcomes. The number of observations available varies for the different life outcomes: subjective health $(14,218)$, life satisfaction $(14,214)$, gross wage $(7,199)$, unemployed $(9,095)$, and years of education $(13,768)$. Gross wage measures the gross hourly wage.

All reported correlation structures indicate that personality and preference measures are far from perfectly substitutable. To determine whether they actually complement each other, we now analyze their explanatory power with respect to important life outcomes. To that end we again use data from the SOEP. In particular, we consider the following outcomes: subjective health, life satisfaction, gross wage, being unemployed and years of education. For each outcome we estimate linear regression models in which outcomes are regressed on the set of economic preferences, the Big Five and the locus of control, separately as well as jointly. ${ }^{23}$ The idea is to assess the explanatory power of each concept in

\footnotetext{
${ }^{23}$ The corresponding regressions are shown in Table A.5 in the appendix.
} 
isolation and in combination. This enables us to check the extent to which explanatory power increases when combining the concepts and thus allows us to reach conclusions regarding the degree of their complementarity. The criterion used to compare differences in explanatory power is adjusted $R^{2}$.

All life outcomes we use come from the 2009 wave of the SOEP. Subjective health was measured on a five-point-scale, from "very good" to "bad". We reverse the answer scale such that higher values indicate a better subjective health status. Life satisfaction was elicited using the question "How satisfied are you with your life, all things considered?", which was answered on an 11-point-scale (with higher values indicating higher life satisfaction). Our measure for gross hourly wage is the gross monthly wage divided by monthly working hours. ${ }^{24}$ Unemployment status is a binary variable equal to one if the person was unemployed at the time of the survey and zero otherwise. The variable years of education is created by adding up years of schooling and additional occupational training (including university). ${ }^{25}$

Figure 1 shows adjusted $R^{2}$ 's for the different life outcomes. $R^{2}$ values for the three concepts - Big Five, Locus of Control and economic preferences - in isolation range from $1 \%$ to $10 \%$ and vary both between concepts and outcomes. Thus, they contribute to explaining heterogeneity in important life outcomes. ${ }^{26}$ More important in light of our research question, however, is that the explanatory power is considerably larger when combining the Big Five, the locus of control and economic preferences compared to using each concept individually. Moreover, explanatory power is always maximized when all three concepts are included in the regression, hereafter referred to as the full model. In this case, resulting adjusted $R^{2}$ values reach levels of about $6 \%$ to $18 \%$. This clearly indicates the existence of important complementarities among the different concepts. ${ }^{27}$

\footnotetext{
${ }^{24}$ Monthly working hours are calculated as the average weekly working hours multiplied by four.

${ }^{25}$ For each school degree and occupational training (including university) official standard graduation times in years are used for the calculation.

${ }^{26}$ In the explanation of life outcomes such as gross wages, unemployment and years of education the preference for work versus leisure would probably play a key role. However, no question related to this preference was included in the survey.

${ }^{27}$ For an overview over the raw correlations between each preference and personality trait and life outcomes see Figure A.3 and A.4 in Section ??.
} 
Because the question here is one of model selection, we also employ model selection criteria (in particular the Akaike and Bayesian information criterion) to check whether the full model is also chosen by model selection criteria. As can be seen in Table A.6 in the appendix this is the case for all life outcomes considered, corroborating our previous results. We perform the same analysis using binary and ordered choice models when appropriate. Again, the full model is chosen by the model selection criteria in all cases. As another robustness check we consider more flexible models: Along with including each predictor linearly in our regressions we also include square terms and all possible cross-products (see Table A.7 in the appendix). Again the full model obtains the highest adjusted $R^{2}$ measures when using ordinary-least-squares estimation and is also chosen by the information criteria in nearly all cases. ${ }^{28}$ Results are again robust for employing binary and ordered choice models when appropriate. Moreover, in all models considered the joint hypothesis that all coefficients are equal to zero is always rejected at the 1\% level (Tables A.6 and A.7 in the appendix). In summary, sizeable complementarities among the different concepts are corroborated in all robustness checks.

\section{Discussion}

In this review we examine the relation between economic preferences and personality using three different data sets. We find no indication for a strong linear or a non-linear association between the two. Thus we conclude that the two concepts cannot substitute for each other. In fact, with regard to explaining heterogeneity in life outcomes, we find that the two concepts play complementary roles. Our findings imply that researchers in economics and psychology can benefit greatly from the respective disciplines when looking for potential sources of heterogeneity in life outcomes.

The finding of a rather low association between economic preferences and psychological measures of personality is perhaps not surprising. First, both concepts are constructed in

\footnotetext{
${ }^{28}$ Only the Bayesian information criterion chooses a model just including the locus of control when it comes to explaining gross wage and unemployment. However, this is not surprising given the number of regressors included and the tendency of Bayesian information criterion to choose parsimonious models.
} 
very different ways. Whereas preferences are rooted in utility theory, derived in terms of specific functional forms of utility functions, the Big Five personality indicators originate in language analysis. Second, the Big Five measure rather broad aspects of personality. In particular, each dimension of the Big Five is by itself already an aggregation of different attitudes or subfacets. Thus, although our results show low associations between personality and economic preferences, we cannot exclude the possibility that there is a stronger degree of association between economic preferences and subfacets of the five personality traits. The trait extraversion, for example, comprises different attitudes, such as being "relatively outgoing, gregarious, sociable, and openly expressive" (see Table A.1), measured by 12 different questions in the NEO-FFI or three different questions in the BFI-S. In other words, each personality measure is not only comprises multiple items, but more importantly captures distinct aspects of a character trait. Economic preferences, conversely, are defined more narrowly. For example, the concept of time preferences refers to the individual's willingness to abstain from something in the present in order to benefit from that decision in the future. Although this concept is applicable to different domains (e.g., to health outcomes or financial decision making) the underlying concept remains the same and is measured by standard incentivized experiments or survey items as employed in this study. In this sense, our preference measures might resemble the subordinate aspects of the five personality factors.

Third, the finding of strong complementarities between economic preferences and personality measures may simply reflect conceptual differences in the way economic and psychological models are constructed. The economic model explains heterogeneity in behavior in terms of three distinct components: preferences, beliefs and constraints, such as abilities. In contrast, psychological measures such as the Big Five include notions of preferences as well as beliefs and constraints. In other words, in our analysis we correlate economic preferences at least partly with beliefs and constraints, which by construction should not necessarily be correlated. A good example is conscientiousness. Being able and willing to work hard and being organized comprises aspects of both, preferences and personal abilities. Likewise, emotional instability, which is part of the neuroticism facet, is related to personal inability rather than a preference. Even more extreme is the case of the locus 
of control, which is clearly a belief rather than a preference. This does not rule out the possibility that the two concepts are related, for example, because an external locus of control is conducive to the development of impatient behavior: if it does not pay off to invest because life circumstances are predominantly determined by circumstances beyond my control, the willingness to forgo current consumption and wait in order to earn a return in the future makes little sense. Yet, beliefs and preferences are two distinct concepts.

The main focus of this review is the rather weak association and complementary nature of economic and psychological measures of personality. We do not discuss the specific signs of the correlations or ways to integrate personality into the economic model. Important work in this direction has been done by Almlund et al., 2011. Many signs of the correlations reported above are consistent across the three data sets, in particular those that are significant. For example, in all three data sets risk attitudes and extraversion are positively correlated, and risk and neuroticism are negatively correlated. There are important exceptions, however. In the student sample, for example, risk attitudes and openness are negatively correlated, whereas they are positively and significantly negatively correlated in the two representative data sets. These and other inconsistencies raise important questions. One possible reason for finding different signs is the use of different elicitation methods for economic preferences (experiments and survey responses). Another possibility is that the reported correlations vary over the life-cycle. If traits develop with different speed and at different points in life correlations should vary with age. This could explain differences between a relatively young student sample and the representative samples. Not much is known about how economic preferences develop over the life-cycle but at least for risk attitudes there seems to be a robust and large negative age effect on willingness to take risks (Dohmen et al., 2011). Another possibility is that preferences and personality are generically differentially correlated between specific groups of the population (e.g., varying by gender, age, height or education). From an evolutionary perspective the co-evolution of traits may serve different purposes depending on specific life circumstances. It may be "optimal" for one subgroup of the population to develop a positive correlation among particular traits, whereas for another subgroup it is adaptive to form a negative correlation. More work needs to be done to uncover potential group-specific correlations between per- 
sonality and preferences.

The approach taken above is agnostic in the sense that we simply correlate existing and important measurement systems as they are. We think this is an important exercise but it can only be a first step. What is needed is the development of a comprehensive framework that combines insights from the approaches taken by economists and psychologists to capture sources of heterogeneity in behavior. It is surprising that the Big Five apparently misses important preferences such as attitudes towards risk and time. Similarly, the economic model is incomplete not only with respect to important preferences, but also with respect to heterogeneity in abilities and beliefs. In the standard economic framework, beliefs are assumed to be endogenous to the strategic situation and formed in a rational way. Perhaps, with the exception of interpersonal trust, beliefs are typically assumed to follow common prior assumptions and rational updating. The role of the locus of control in explaining fundamental life outcomes on top of preferences, however, reveals the importance of enduring and individual specific belief systems. Other examples include optimism, pessimism, religious beliefs and ideological beliefs. The stability of belief heterogeneity is not well understood. It probably originates in different priors inherited from parents, self-selection into peer groups and institutions with reinforcing belief characteristics and boundedly rational belief formation, such as selected perception, non-Bayesian updating and ego utility (Köszegi, 2006). Regardless of the precise channels that support enduring heterogeneous beliefs, economics would largely benefit from measuring and including them in explanations of economic outcomes. In addition, economists have started to model the fact that preferences and beliefs are intimately related and not separable as traditionally assumed. In fact, people often want to believe certain things, for example, in terms of being liked by others or being better than others (overconfidence). Finally, another important extension of the economic model would be the measurement of person-specific abilities. Whereas IQ has become a standard individual-specific characteristic to be included in outcome regressions, little work has acknowledged the importance of other competencies captured by Big Five traits, for example, the role of conscientiousness for educational or labor market outcomes. 


\section{References}

Allport GW, Odbert HS. 1936. Traitnames. a psycho-lexical study. Psychological Monographs 47: 171.

Almlund M, Duckworth A, Heckman J, Kautz T. 2011. Personality Psychology and Economics. IZA DP No. 5500 .

Anderson J, Burks S, DeYoung C, Rustichini A. 2011. Toward the Integration of Personality Theory and Decision Theory in the Explanation of Economic Behavior. mimeo .

Ben-Ner A, Kramer A. 2010. Personality and Altruism in the Dictator Game: Relationship to Giving to Kin, Collaborators, Competitors, and Neutrals. Personality and Individual Differences 51: 216-221.

Berg J, Dickhaut J, McCabe K. 1995. Trust, Reciprocity, and Social History. Games and Economic Behavior 10: $122-142$.

Bibby P, Ferguson E. 2010. The Ability to Process Emotional Information Predicts Loss Aversion. Personality and Individual Differences 51: 263-266.

Borghans L, Duckworth AL, Heckman JJ, ter Weel B. 2008. The Economics and Psychology of Personality Traits. Journal of Human Resources 43: 972-1059.

Borghans L, Golsteyn B, Heckman J, Meijers H. 2009. Gender Differences in Risk Aversion and Ambiguity Aversion. Journal of the European Economic Association 7: 649-658.

Cohen J. 1988. Statistical power analysis for the social sciences (2nd ed.). Hillsdale, NJ: Erlbaum.

Cohen J. 1992. A Power Primer. Psychological Bulletin 112: 155-159.

Costa P, McCrae R. 1989. NEO-PI/FFI manual supplement. Odessa, FL: Psychological Assessment Resources.

Costa P, McCrae R. 1992. Revised NEO Personality Inventory (NEO PI-R) and NEO Five-Factor Inventory (NEO-FFI). Odessa, FL, Psychological Assessment Resources.

Daly M, Delaney L, Harmon C. 2009. Psychological and Biological Foundations of Time Preferences. Journal of the European Economic Association 7: 659-669.

Dohmen T, Falk A, Huffman D, Sunde U. 2008. Representative Trust and Reciprocity: Prevalence and Determinants. Economic Inquiry 46: 84-90.

Dohmen T, Falk A, Huffman D, Sunde U. 2009. Homo Reciprocans: Survey Evidence on Behavioral Outcomes. Economic Journal 119: 592-612.

Dohmen T, Falk A, Huffman D, Sunde U. 2010. Are Risk Aversion and Impatience Related to Cognitive Ability? American Economic Review 100: 1238-1260.

Dohmen T, Falk A, Huffman D, Sunde U. 2011. Individual Risk Attitudes: Measurement, Determinants, and Behavioral Consequences. Journal of the European Economic Association 9: 522-550.

Eckel C, Grossmann P. 1996. Altruism in Anonymous Dictator Games. Games and Economic Behavior 16: $181-191$.

Eckel C, Grossmann P. 2002. Sex Differences and Statistical Stereotyping in Attitudes Toward Financial 
Risk. Evolution and Human Behavior 23: 281-295.

Falk A, Dohmen T, Huffman D, Sunde U, Becker A. 2011. A validated preference module. mimeo .

Falk A, Fehr E, Fischbacher U. 2005. Driving forces behind informal sanctions. Econometrica 73: 20172030.

Falk A, Fischbacher U. 2006. A Theory of Reciprocity. Games and Economic Behavior 54: $293-315$.

Fehr E. 2009. On the Economics and Biology of Trust. Journal of the European Economic Association 7: 235-266.

Fischbacher U. 2007. ztree: Zurich Toolbox for Ready-made Economic Experiments. Experimental Economics 10: 171-178.

Frederick S, Loewenstein G, O’Donoghue T. 2002. Time Discounting and Time Preference: A Critical Review. Journal of Economic Literature 40: 351-401.

Gerlitz JY, Schupp J. 2005. Zur Erhebung der Big-Five-basierten Persönlichkeitsmerkmale im SOEP. DIW Berlin, Research Notes .

Gollier C. 2001. The Economics of Risk and Time. Cambridge, MA: MIT Press.

Greiner B. 2004. An online recruitment system for economic experiments. Forschung und wissenschaftliches Rechnen 63: 79-93.

Köszegi B. 2006. Ego Utility, Overconfidence, and Task Choice. Journal of the European Economic Association 4: $673-707$.

Manski C. 2002. Identification of decision rules in experiments on simple games of proposal and response. European Economic Review 46: 880-891.

Roberts BW. 2006. Personality Development and Organizational Behavior. In B. M. Staw (Ed.). Research on Organizational Behavior. Elsevier Science/JAI Press, pages 1-41.

Roberts BW. 2009. Back to the Future: Personality and Assessment and Personality Development. Journal of Research in Personality 43: 137-145.

Rotter J. 1966. Generalized expectancies for internal versus external control of reinforcement. Psychological Monographs 80: 1-28.

Samuelson P. 1937. A Note on Measurement of Utility. Review of Economic Studies 4: 155-161.

Schupp J, Wagner GG. 2002. Maintenance of and Innovation in Long-Term Panel Studies The Case of the German Socio-economic panel (GSOEP). Allgemeines Statistisches Archiv 86: 163-175.

Selten R. 1967. Die Strategiemethode zur Erforschung des eingeschränkt rationalen Verhaltens im Rahmen eines Oligopolexperiments. In: Sauermann, H. (Ed.), Beiträge zur experimentellen Wirtschaftsforschung. J.C.B. Mohr (Paul Siebeck), Tübingen.

Vischer T, Dohmen T, Falk A, Huffman D, Schupp J, Sunde U, Wagner G. 2011. Measuring Time Preferences in Representative Samples by Combining Experimental Elicitation and Survey Measures. mimeo .

Wagner GG, Frick JR, Schupp J. 2007. The German Socio-Economic Panel Study (SOEP) - Evolution, 
Scope and Enhancements. SOEPpapers 1, DIW Berlin, The German Socio-Economic Panel (SOEP) .

Zuckerman M. 1994. Behavioral Expressions and Biosocial Bases of Sensation Seeking. New York, Cambridge University Press. 


\section{Appendix}

Table A.1: Definitions of the Big Five Domains

\begin{tabular}{l|l}
\hline \hline \multicolumn{1}{l}{ Big Five Domain } & \multicolumn{1}{c}{ APA Dictionary Definition } \\
\hline Openness & $\begin{array}{l}\text { Individual differences in the tendency to be open } \\
\text { to new aesthetic, cultural, and intellectual experiences. }\end{array}$ \\
\hline Conscientiousness & $\begin{array}{l}\text { The tendency to be organized, responsible, and hardworking; } \\
\text { located at one end of a dimension of individual differences: } \\
\text { conscientiousness vs. lack of direction. }\end{array}$ \\
\hline Extraversion & $\begin{array}{l}\text { An orientation of ones interests and energies toward the } \\
\text { outer world of people and things rather than the inner } \\
\text { world of subjective experience; includes the quality of being } \\
\text { more outgoing, gregarious, sociable, and openly expressive. }\end{array}$ \\
\hline Agreeableness & $\begin{array}{l}\text { The tendency to act in a cooperative, unselfish manner; } \\
\text { located at one end of a dimension of individual } \\
\text { differences: agreeableness vs. disagreeableness. }\end{array}$ \\
\hline Neuroticism & $\begin{array}{l}\text { A chronic level of emotional instability } \\
\text { and proneness to psychological distress. }\end{array}$ \\
\hline \hline
\end{tabular}

This table is in parts reproduced from Borghans et al. (2008).

Table A.3: Spearman correlation structure representative experimental data

\begin{tabular}{l|ccccc}
\hline \hline & Openness & Conscientiousness & Extraversion & Agreeableness & Neuroticism \\
Time & -0.0199 & -0.0737 & $-0.0764^{*}$ & $-0.0829^{*}$ & -0.0598 \\
Risk & $0.1315^{*}$ & -0.0744 & 0.0661 & $-0.0854^{*}$ & -0.0261 \\
\hline \hline
\end{tabular}

${ }^{*},{ }^{* *}$, and ${ }^{* * *}$ indicate significance at the $10 \%, 5 \%$, and $1 \%$ level. All measures are standardized. 


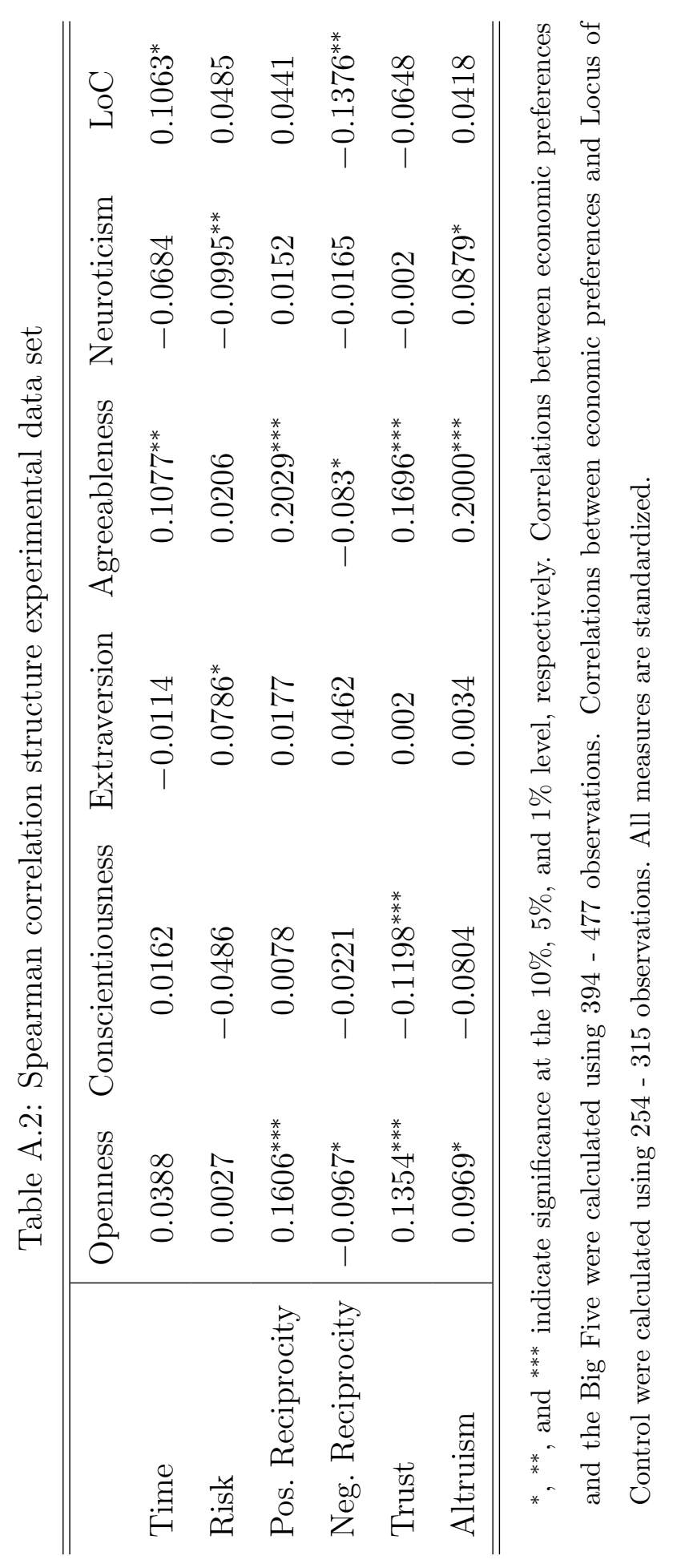




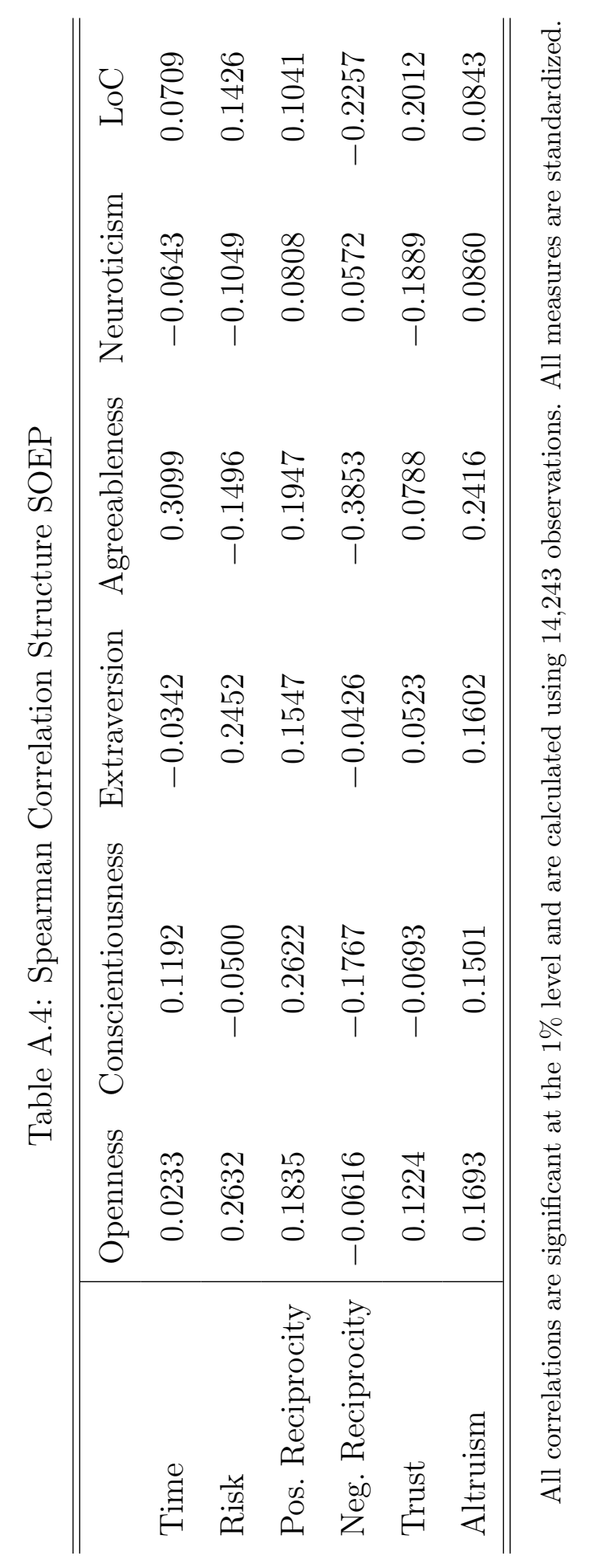


Figure A.1: Kernel-weighted local linear polynomial regressions using experimental data
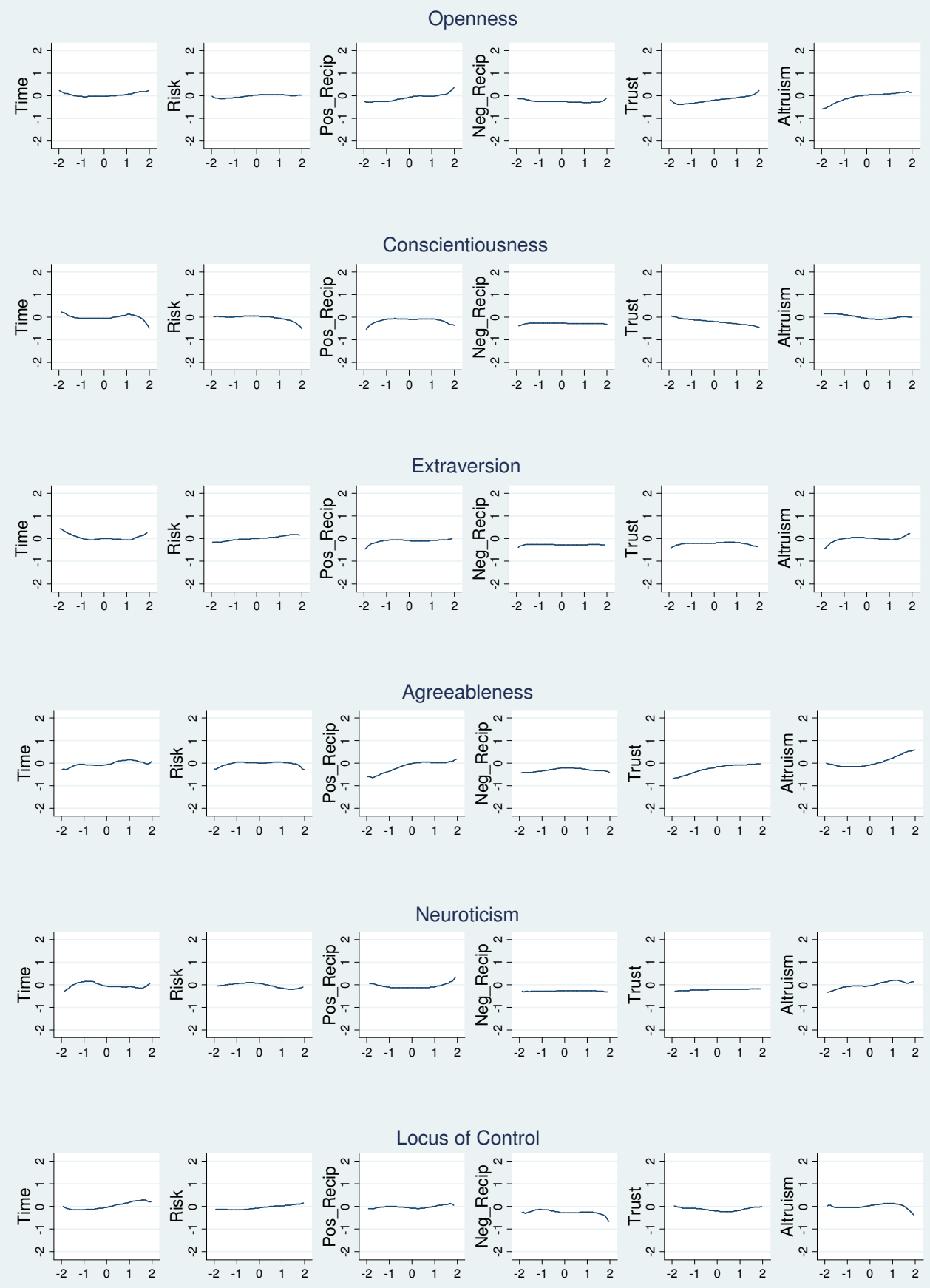
Figure A.2: Kernel-weighted local linear polynomial regressions using SOEP data
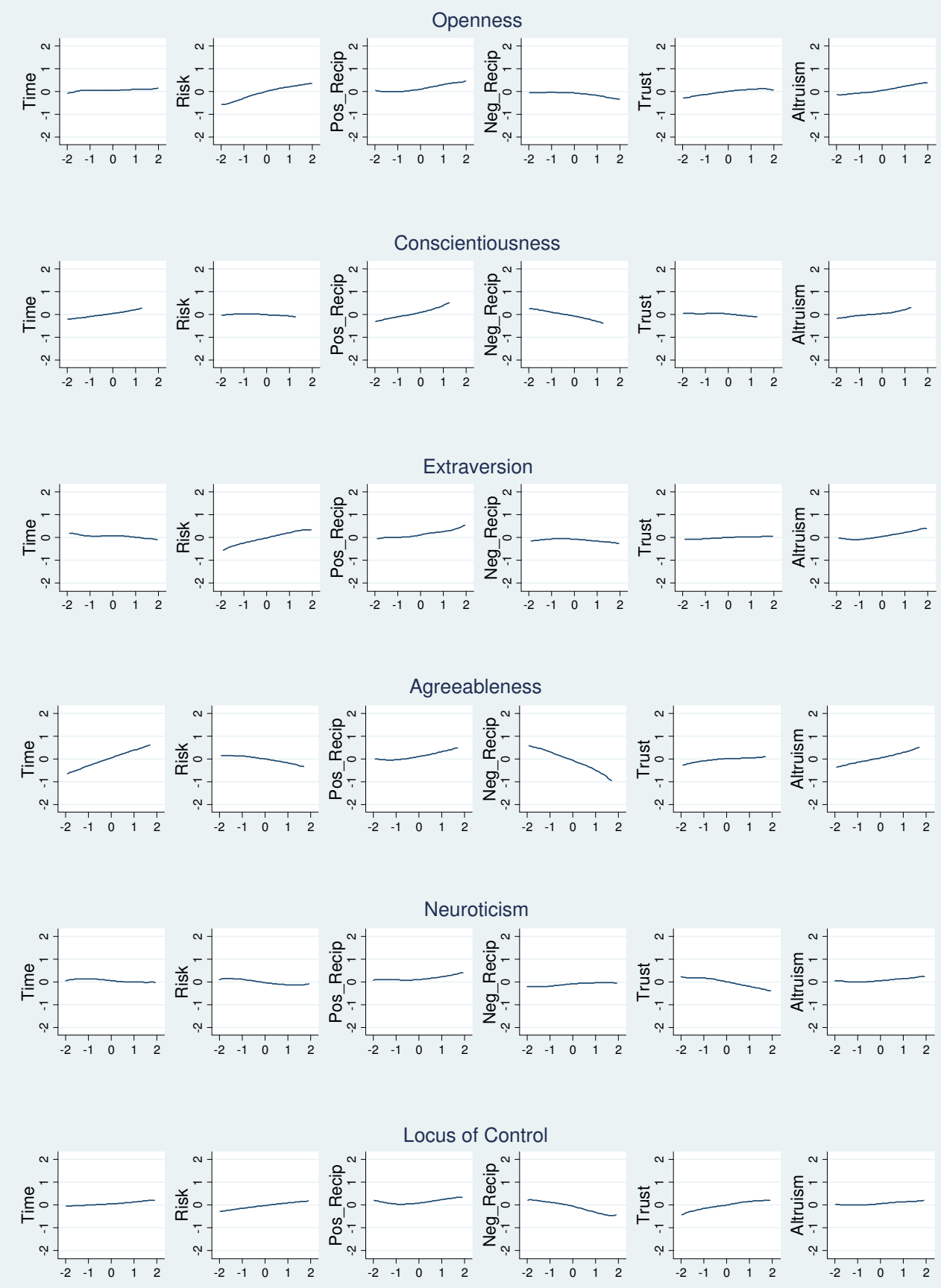
Table A.5: Outcome Regressions: Representative Experimental Data

\begin{tabular}{|c|c|c|c|c|c|}
\hline & (1) & $(2)$ & (3) & (4) & $(5)$ \\
\hline Life Outcomes & Subj. Health & Life Satisf. & Gross Wage & Unemployed & Years of Educ. \\
\hline \multirow[t]{2}{*}{ Openness } & $0.043^{* * *}$ & $0.123^{* * *}$ & $0.989^{* * *}$ & $-0.018^{* * *}$ & $0.667^{* * *}$ \\
\hline & $(0.009)$ & $(0.017)$ & $(0.162)$ & $(0.004)$ & $(0.027)$ \\
\hline \multirow[t]{2}{*}{ Conscientiousn. } & $0.038^{* * *}$ & $0.106^{* * *}$ & $0.565^{* * *}$ & $-0.014^{* * *}$ & $-0.182^{* * *}$ \\
\hline & $(0.009)$ & $(0.017)$ & $(0.161)$ & $(0.004)$ & $(0.026)$ \\
\hline \multirow[t]{2}{*}{ Extraversion } & $0.026^{* * *}$ & $0.134^{* * *}$ & $-1.201^{* * *}$ & $0.006^{*}$ & $-0.309 * * *$ \\
\hline & $(0.009)$ & $(0.017)$ & $(0.154)$ & $(0.004)$ & $(0.026)$ \\
\hline \multirow[t]{2}{*}{ Agreeableness } & $0.033^{* * *}$ & $0.139 * * *$ & $-1.288^{* * *}$ & $0.023^{* * *}$ & $-0.146^{* * *}$ \\
\hline & $(0.010)$ & $(0.018)$ & $(0.165)$ & $(0.004)$ & $(0.028)$ \\
\hline \multirow[t]{2}{*}{ Neuroticism } & $-0.140^{* * *}$ & $-0.186^{* * *}$ & $-1.009^{* * *}$ & $0.018^{* * *}$ & $-0.272^{* * *}$ \\
\hline & $(0.009)$ & $(0.016)$ & $(0.158)$ & $(0.004)$ & $(0.026)$ \\
\hline \multirow[t]{2}{*}{$\mathrm{LoC}$} & $0.105^{* * *}$ & $0.307^{* * *}$ & $1.899 * * *$ & $-0.043^{* * *}$ & $0.421^{* * *}$ \\
\hline & $(0.008)$ & $(0.015)$ & $(0.145)$ & $(0.003)$ & $(0.024)$ \\
\hline \multirow[t]{2}{*}{ Patience } & $0.024^{* * *}$ & $0.129 * * *$ & $-0.343^{* *}$ & 0.001 & $-0.151^{* * *}$ \\
\hline & $(0.008)$ & $(0.015)$ & $(0.136)$ & $(0.003)$ & $(0.023)$ \\
\hline \multirow[t]{2}{*}{ Risk } & $0.131^{* * *}$ & $0.076^{* * *}$ & $0.415^{* *}$ & 0.003 & $0.210^{* * *}$ \\
\hline & $(0.009)$ & $(0.017)$ & $(0.166)$ & $(0.004)$ & $(0.027)$ \\
\hline \multirow[t]{2}{*}{ Pos. Recip. } & $-0.035^{* * *}$ & 0.006 & $0.388^{* * *}$ & -0.002 & 0.005 \\
\hline & $(0.008)$ & $(0.015)$ & $(0.140)$ & $(0.003)$ & $(0.023)$ \\
\hline \multirow[t]{2}{*}{ Neg. Recip. } & $0.064^{* * *}$ & $0.039^{* *}$ & $-0.329^{* *}$ & $0.006^{*}$ & $-0.137^{* * *}$ \\
\hline & $(0.008)$ & $(0.015)$ & $(0.147)$ & $(0.003)$ & $(0.024)$ \\
\hline \multirow[t]{2}{*}{ Trust } & $0.122^{* * *}$ & $0.308^{* * *}$ & $1.763^{* * *}$ & $-0.035^{* * *}$ & $0.587^{* * *}$ \\
\hline & $(0.009)$ & $(0.015)$ & $(0.145)$ & $(0.003)$ & $(0.024)$ \\
\hline \multirow[t]{2}{*}{ Altruism } & $0.070^{* * *}$ & $0.072^{* * *}$ & $-0.780^{* * *}$ & 0.005 & $0.084^{* * *}$ \\
\hline & $(0.009)$ & $(0.016)$ & $(0.152)$ & $(0.003)$ & $(0.025)$ \\
\hline \multirow[t]{2}{*}{ Constant } & $3.300^{* * *}$ & $6.852^{* * *}$ & $16.100^{* * *}$ & $0.099^{* * *}$ & $12.346^{* * *}$ \\
\hline & $(0.007)$ & $(0.014)$ & $(0.131)$ & $(0.003)$ & $(0.021)$ \\
\hline Observations & 14,218 & 14,214 & 7,199 & 9,095 & 13,768 \\
\hline Adj. R-squared & 0.108 & 0.159 & 0.0919 & 0.0547 & 0.174 \\
\hline
\end{tabular}

${ }^{*},{ }^{* *}$, and ${ }^{* * *}$ indicate significance at the $10 \%, 5 \%$, and $1 \%$ level, respectively. All measures are standardized. 
Figure A.3: Correlation Coefficients Between Preference Measures and Life Outcomes Using SOEP Data

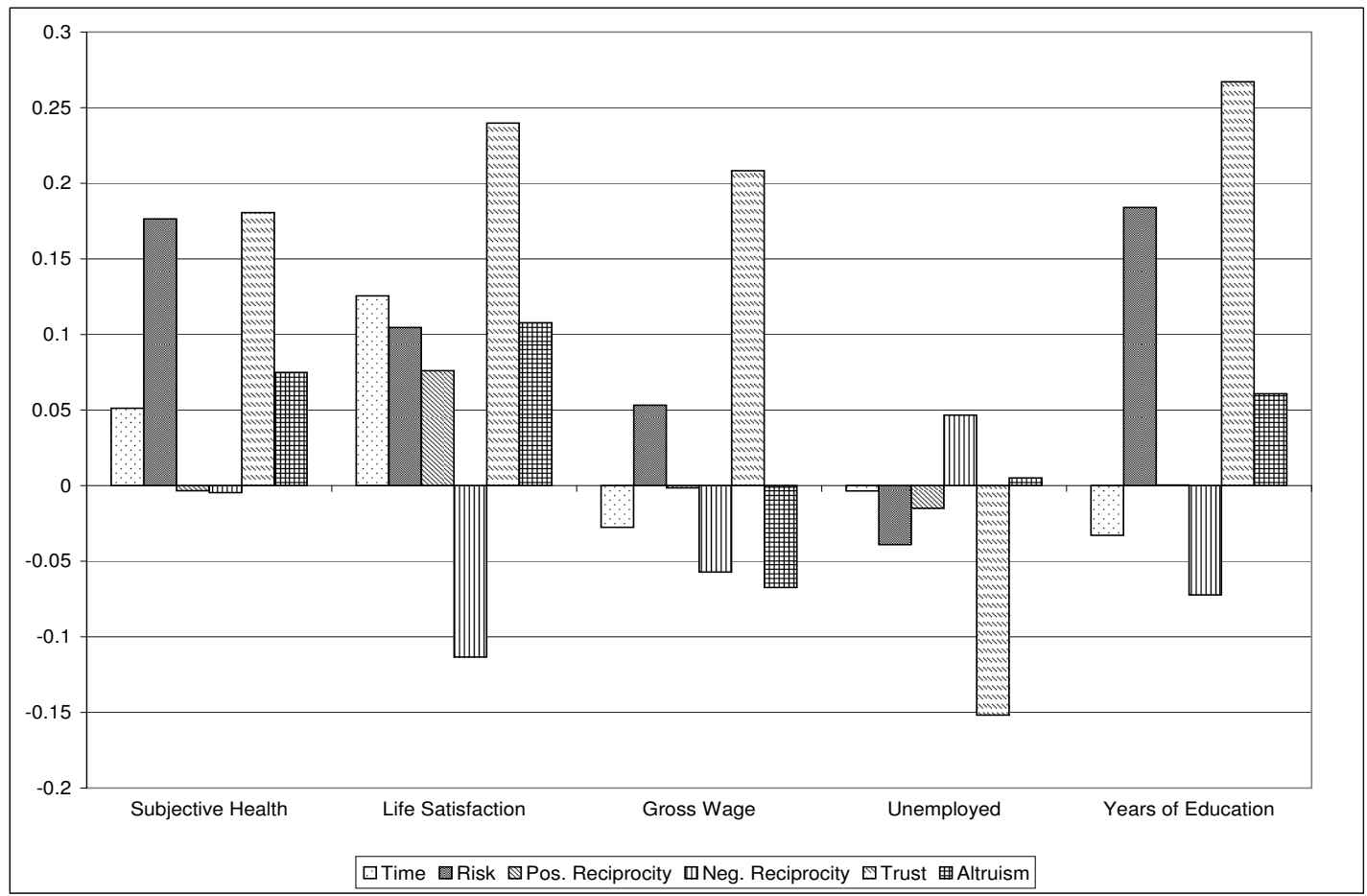

Pearson correlation coefficients between preference measures and life outcomes using SOEP data. Trust always shows the strongest association with life outcomes. More trust and a higher willingness to take risk are always related to better life outcomes, e.g. better health and greater life satisfaction, whereas negative reciprocity is associated with less life satisfaction and lower wages. The number of observations available varies for the different life outcomes: subjective health $(14,218)$, life satisfaction $(14,214)$, gross wage $(7,199)$, unemployed $(9,095)$, years of education $(13,768)$. Gross wage measures the gross hourly wage. 
Figure A.4: Correlation Coefficients Between Personality Measures and Life Outcomes Using SOEP Data

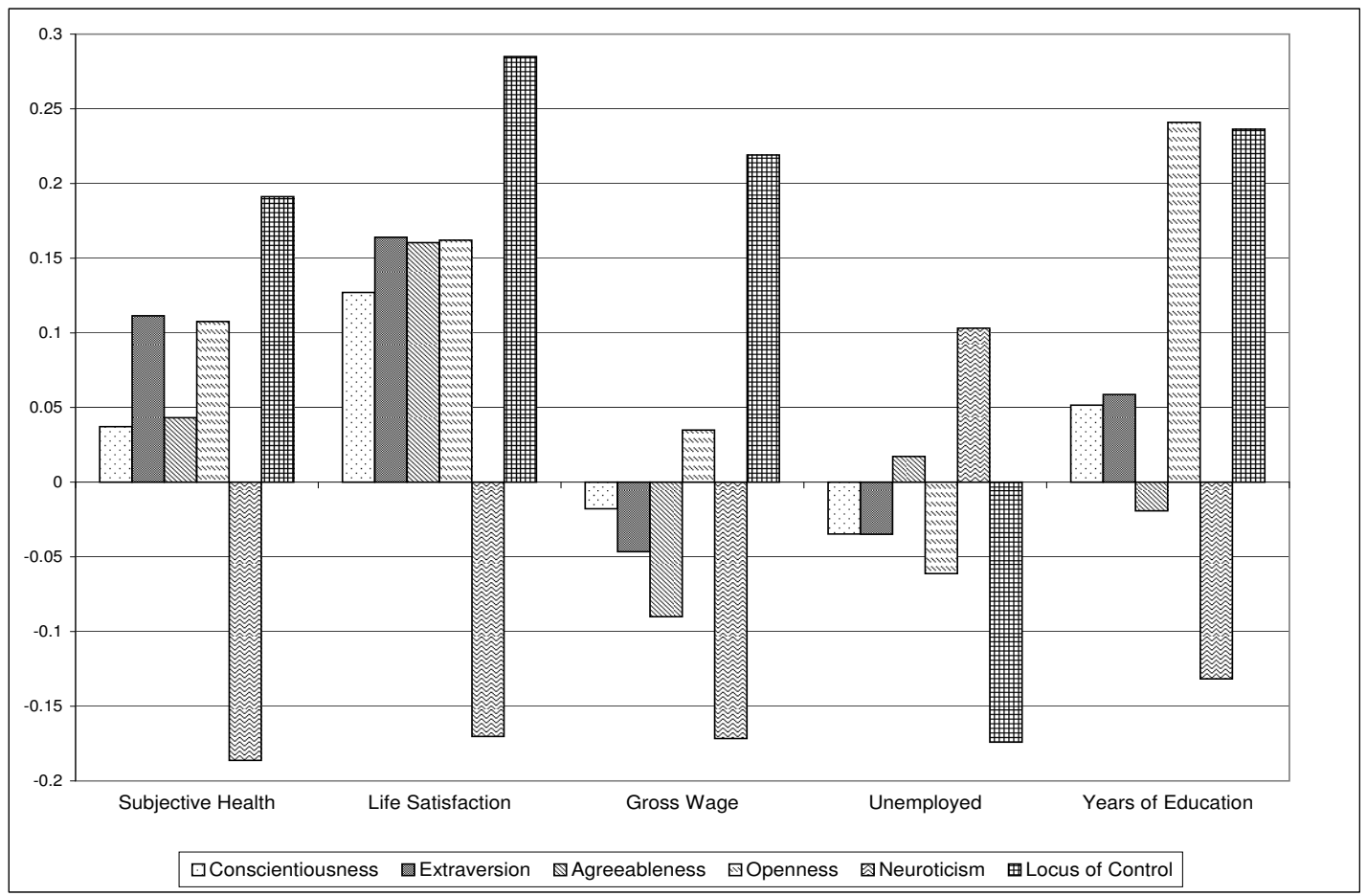

Pearson correlation coefficients between personality measures and life outcomes using SOEP data. The locus of control and neuroticism show the strongest associations with life outcomes. A more internal locus of control is always related to better outcomes (e.g. better health or more life satisfaction), whereas a higher degree of neuroticism is associated with lower wages or a higher probability of being unemployed. The number of observations available varies for the different life outcomes: subjective health $(14,218)$, life satisfaction $(14,214)$, gross wage $(7,199)$, unemployed $(9,095)$, years of education $(13,768)$. Gross wage measures the gross hourly wage. 
Table A.6: Linear representation of outcome regressions

\begin{tabular}{|c|c|c|c|c|c|c|c|c|c|c|}
\hline & \multicolumn{5}{|c|}{ Subjective Health (OLS) } & \multicolumn{5}{|c|}{ Subjective Health (o. probit) } \\
\hline & Big5 & $\mathrm{LoC}$ & Pref & Big5-Pref & Big5-Pref-LoC & Big5 & $\mathrm{LoC}$ & Pref & Big5-Pref & Big5-Pref-LoC \\
\hline adj. $R^{2} /$ pseudo $R^{2}$ & 0.0561 & 0.0383 & 0.0688 & 0.0975 & 0.1075 & 0.0220 & 0.0145 & 0.0268 & 0.0388 & 0.0429 \\
\hline F-Test/LR-Test & 170.04 & 567.35 & 176.01 & 140.59 & 143.72 & 834.99 & 550.62 & 1016.47 & 1471.22 & 1627.11 \\
\hline AIC & 37833 & 38094 & 37641 & 37201 & $\underline{37043}$ & 37139 & 37415 & 36960 & 36515 & $\underline{36361}$ \\
\hline \multirow[t]{3}{*}{$\mathrm{BIC}$} & 37878 & 38109 & 37694 & 37292 & $\underline{37142}$ & 37207 & 37453 & 37035 & 36628 & $\underline{36482}$ \\
\hline & \multicolumn{5}{|c|}{ Life Satisfaction (OLS) } & \multicolumn{5}{|c|}{ Life Satisfaction (o. probit) } \\
\hline & Big5 & LoC & Pref & Big5-Pref & Big5-Pref-LoC & & & & & \\
\hline adj. $R^{2} /$ pseudo $R^{2}$ & 0.0899 & 0.0782 & 0.0917 & 0.1342 & 0.1588 & 0.0261 & 0.0219 & 0.0256 & 0.0390 & 0.0467 \\
\hline F-Test/LR-Test & 281.88 & 1206.91 & 240.08 & 201.27 & 224.67 & 1406.38 & 1178.16 & 1376.73 & 2098.73 & 2513.61 \\
\hline AIC & 55038 & 55216 & 55012 & 54335 & $\underline{53926}$ & 52448 & 52668 & 52480 & 51768 & $\underline{51355}$ \\
\hline \multirow[t]{3}{*}{$\mathrm{BIC}$} & 55083 & 55231 & 55065 & 54426 & $\underline{54024}$ & 52561 & 52751 & 52601 & 51926 & $\underline{51521}$ \\
\hline & \multicolumn{5}{|c|}{ Gross Wage(OLS) } & & & & & \\
\hline & Big5 & LoC & Pref & Big5-Pref & Big5-Pref-LoC & - & - & - & - & - \\
\hline adj. $R^{2} /$ pseudo $R^{2}$ & 0.0361 & 0.0388 & 0.0456 & 0.0704 & 0.0919 & - & - & - & - & - \\
\hline F-Test/LR-Test & 54.97 & 291.20 & 58.31 & 50.57 & 61.71 & - & - & - & - & - \\
\hline AIC & 55088 & 55088 & 55042 & 54857 & $\underline{54690}$ & - & - & - & - & - \\
\hline \multirow[t]{3}{*}{$\mathrm{BIC}$} & 55102 & 55102 & 55090 & 54940 & $\underline{54779}$ & - & - & - & - & - \\
\hline & \multicolumn{5}{|c|}{ Unemployed (OLS) } & \multicolumn{5}{|c|}{ Unemployed (probit) } \\
\hline & Big5 & $\mathrm{LoC}$ & Pref & Big5-Pref & Big5-Pref-LoC & Big5 & $\mathrm{LoC}$ & Pref & Big5-Pref & Big5-Pref-LoC \\
\hline adj. $R^{2} /$ pseudo $R^{2}$ & 0.0191 & 0.0331 & 0.0245 & 0.0375 & 0.0547 & 0.0322 & 0.0527 & 0.0412 & 0.0648 & 0.0926 \\
\hline F-Test/LR-Test & 36.34 & 312.13 & 39.05 & 33.22 & 44.82 & 180.12 & 294.52 & 230.37 & 361.89 & 517.42 \\
\hline AIC & 3067 & 2932 & 3017 & 2900 & $\underline{2738}$ & 5420 & 5298 & 5372 & 5250 & $\underline{5097}$ \\
\hline \multirow[t]{3}{*}{$\mathrm{BIC}$} & 3110 & 2946 & 3067 & 2986 & $\underline{2830}$ & 5463 & 5312 & 5422 & 5336 & $\underline{5189}$ \\
\hline & \multicolumn{5}{|c|}{ Years of Education (OLS) } & \multicolumn{5}{|c|}{ Years of Education (o. probit) } \\
\hline & Big5 & $\mathrm{LoC}$ & Pref & Big5-Pref & Big5-Pref-LoC & & & & & \\
\hline adj. $R^{2} /$ pseudo $R^{2}$ & 0.0914 & 0.0525 & 0.1061 & 0.1545 & 0.1736 & 0.0209 & 0.0126 & 0.0241 & 0.0359 & 0.0415 \\
\hline F-Test/LR-Test & 277.93 & 763.89 & 273.29 & 229.74 & 242.03 & 1355.80 & 817.10 & 1563.14 & 2329.14 & 2688.38 \\
\hline $\mathrm{AIC}$ & 65506 & 66078 & 65282 & 64520 & $\underline{64206}$ & 63490 & 64021 & 63285 & 62529 & $\underline{62171}$ \\
\hline $\mathrm{BIC}$ & 65551 & 66093 & 65335 & 64610 & $\underline{64304}$ & 63641 & 64141 & 63443 & 62724 & $\underline{62375}$ \\
\hline
\end{tabular}

For the ordinary-least-squares (OLS) models we calculate $R^{2}$, whereas for the ordinal models we calculate pseudo $R^{2}$. The joint significance of all coefficients is tested using the F-test (OLS) and the LR-test (ordinal models). All F- and LR-tests are significant at the $1 \%$ level. With regard to the Akaike information criterion (AIC) and Bayesian information criterion (BIC), the smallest value for each outcome regression is underlined. Note that the full model (including the Big 5, locus of control and preferences) is always chosen by both information criteria. The number of observations available varies for the different life outcomes: subjective health $(14,218)$, life satisfaction $(14,214)$, gross wage $(7,199)$, unemployed $(9,095$ obs.), and years of education $(13,768)$. Gross wage measures the gross hourly wage. 
Table A.7: Outcome Regressions: Flexible Specification

\begin{tabular}{|c|c|c|c|c|c|c|c|c|c|c|}
\hline & \multicolumn{5}{|c|}{ Subjective Health (OLS) } & \multicolumn{5}{|c|}{ Subjective Health (o. probit) } \\
\hline & Big5 & $\mathrm{LoC}$ & Pref & Big5-Pref & Big5-Pref-LoC & Big 5 & $\mathrm{LoC}$ & Pref & Big5-Pref & Big5-Pref-LoC \\
\hline adj. $R^{2} /$ pseudo $R^{2}$ & .0632 & .0388 & .0714 & .1054 & .1165 & .0251 & .0146 & .0282 & .0435 & .0483 \\
\hline F-Test/LR-Test & 48.99 & 288.17 & 41.48 & 22.75 & 21.83 & 952.98 & 555.19 & 1068.56 & 1651.38 & 1834.03 \\
\hline $\mathrm{AIC}$ & 37740 & 38088 & 37623 & 37142 & $\underline{36977}$ & 37051 & 37413 & 36949 & 36467 & $\underline{36310}$ \\
\hline \multirow[t]{3}{*}{$\mathrm{BIC}$} & 37899 & 38110 & 37834 & 37732 & $\underline{37665}$ & 37232 & 37458 & 37184 & 37079 & $\underline{37021}$ \\
\hline & \multicolumn{5}{|c|}{ Life Satisfaction (OLS) } & \multicolumn{5}{|c|}{ Life Satisfaction (o. probit) } \\
\hline & Big5 & $\mathrm{LoC}$ & Pref & Big5-Pref & Big5-Pref-LoC & Big5 & $\mathrm{LoC}$ & Pref & Big5-Pref & Big5-Pref-LoC \\
\hline adj. $R^{2} /$ pseudo $R^{2}$ & .0948 & .0783 & .0948 & .1397 & .1659 & .0278 & .0219 & .0273 & .0422 & .0505 \\
\hline F-Test/LR-Test & 75.47 & 605.45 & 56.12 & 30.967 & 32.41 & 1493.78 & 1178.45 & 1470.26 & 2273.51 & 2715.76 \\
\hline AIC & 54976 & 55214 & 54984 & 54311 & $\underline{53884}$ & 52391 & 52670 & 52428 & 51725 & $\underline{51309}$ \\
\hline \multirow[t]{3}{*}{$\mathrm{BIC}$} & 55135 & 55237 & 55196 & 54901 & $\underline{54572}$ & 52617 & 52761 & 52708 & 52383 & $\underline{52065}$ \\
\hline & \multicolumn{5}{|c|}{ Gross Wage(OLS) } & & & & & \\
\hline & Big5 & LoC & Pref & Big5-Pref & Big5-Pref-LoC & - & - & - & - & - \\
\hline adj. $R^{2} /$ pseudo $R^{2}$ & .0382 & .0387 & .0527 & .0797 & .1039 & - & - & - & - & - \\
\hline F-Test/LR-Test & 15.30 & 145.74 & 15.84 & 9.092 & 10.27 & - & - & - & - & - \\
\hline $\mathrm{AIC}$ & 55111 & 55090 & 55009 & 54851 & $\underline{54672}$ & - & - & - & - & - \\
\hline \multirow[t]{3}{*}{$\mathrm{BIC}$} & 55256 & $\underline{55111}$ & 55202 & 55388 & 55298 & - & - & - & - & - \\
\hline & \multicolumn{5}{|c|}{ Unemployed (OLS) } & \multicolumn{5}{|c|}{ Unemployed (probit) } \\
\hline & Big5 & $\mathrm{LoC}$ & Pref & Big5-Pref & Big5-Pref-LoC & Big5 & LoC & Pref & $\overline{\text { Big5-Pref }}$ & Big5-Pref-LoC \\
\hline adj. $R^{2} /$ pseudo $R^{2}$ & .0212 & .0385 & .0291 & .0463 & .0705 & .0357 & .0539 & .0498 & .0852 & .1166 \\
\hline F-Test/LR-Test & 10.87 & 183.13 & 11.11 & 6.73 & 8.66 & 199.54 & 301.02 & 278.38 & 475.96 & 651.83 \\
\hline AIC & 3062 & 2882 & 2995 & 2882 & $\underline{2662}$ & 5431 & 5294 & 5366 & 5268 & $\underline{5118}$ \\
\hline \multirow[t]{3}{*}{$\mathrm{BIC}$} & 3211 & $\underline{2903}$ & 3194 & 3437 & 3309 & 5580 & $\underline{5314}$ & 5565 & 5823 & 5766 \\
\hline & \multicolumn{5}{|c|}{ Years of Education (OLS) } & \multicolumn{5}{|c|}{ Years of Education (o. probit) } \\
\hline & Big5 & $\mathrm{LoC}$ & Pref & Big5-Pref & Big5-Pref-LoC & Big5 & $\mathrm{LoC}$ & Pref & Big5-Pref & Big5-Pref-LoC \\
\hline adj. $R^{2} /$ pseudo $R^{2}$ & .1043 & .0525 & .1200 & .1771 & .1982 & .0243 & .0126 & .0281 & .0433 & .0497 \\
\hline F-Test/LR-Test & 81.13 & 382.50 & 70.55 & 39.48 & 38.81 & 1575.60 & 817.25 & 1819.82 & 2808.59 & 3223.85 \\
\hline $\mathrm{AIC}$ & 65324 & 66079 & 65087 & 64213 & $\underline{63869}$ & 63300 & 64023 & 63070 & 62181 & $\underline{61792}$ \\
\hline $\mathrm{BIC}$ & 65482 & 66102 & 65297 & 64800 & $\underline{64554}$ & 63564 & 64151 & 63386 & 62874 & $\underline{62583}$ \\
\hline
\end{tabular}

The outcome variables are regressed on the indicated personality and preference measures. The difference with regard to the linear specification is that the model includes squares of all variables as well as all crossproducts. Cross-products are also calculated between concepts in case more than one concept is included, e.g., in the Big 5-preferences case, we also include the cross-term neuroticicsm*risk. For the ordinary-leastsquares (OLS) models we calculate $R^{2}$, whereas for the ordinal models we calculate pseudo- $R^{2}$. The joint significance of all coefficients is tested using the F-test (OLS models) and the LR-test (ordinal models). All F- and LR-tests are significant at the $1 \%$ level. With regard to the Akaike information criterion (AIC) and Bayesian information criterion (BIC), the smallest value for each outcome regression is underlined. Note that the full model (including the Big 5, locus of control and preferences) is chosen by both information criteria in nearly all cases; only for gross wage and unemployment does the BIC indicate that the model with only $\mathrm{LoC}$ and $\mathrm{LoC}^{2}$ included should be used. The number of observations available varies for the different life outcomes: subjective health $(14,218)$, life satisfaction $(14,214)$, gross wage $(7,199)$, unemployed $(9,095)$, and years of education $(13,768)$. Gross wage measures the gross hourly wage. 